\title{
المرتزقة في القانون الدولي الإنساني
}

\section{حسين نسمة \\ كلية الحقوق \\ جامعة الإخوة منتوري \\ قسنطينة}

المرتزق هو الثخص الذي يشارك مشاركة فعلية

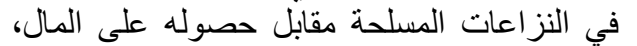

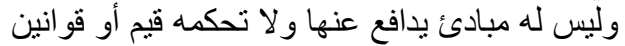

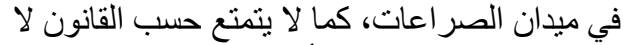
بوصف مقاتل ولا بوضع أسير حرب إذا لـان ما وقع في

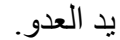

وتعد أفعاله مخالفة لمبادئ الدول المتمدنة ومجرمة

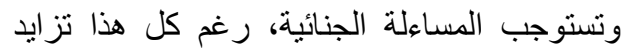
الطلب على استخدام المرنزقة في النزاعات التحات الدولية

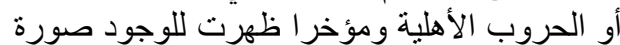

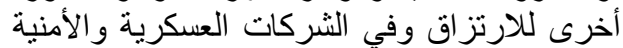

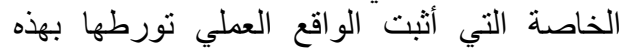

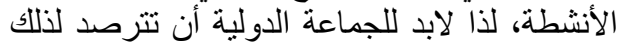
بوضع نظام دولي فعال للمر اقبة و المساءلة.

\section{Abstract:}

عاتت البشرية لفترات طويلة من ويلات الحروب التي خلفت

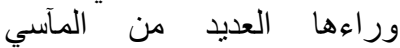
الإنسانية بسبب فناعتها أين كانت الدول تعتبر فيها النصر غايتها المتوخاة دون النظر إلى فئى

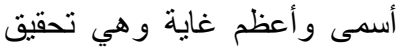
إنسانية الإنسان في هذه الحروبة

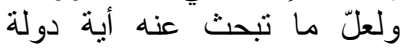

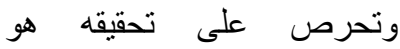
المحافظة قدر المستطاع على الإنى نقاوة الثعور الوطني في الالتزام

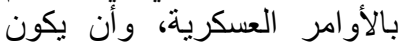
جيشها من مواطنيها، لكن في في لئرن الو اقع توجد بعض من الدول تلجأ في لئي حروبها لاستخدام أثخاص لئول اليسواً

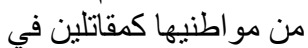

A mercenary is a person who participates actively in armed conflict and he gets money as an exchange, and has no principles for defending and no values or laws control them in the field of conflict, and in law he is not considered as a fighter nor as a prisoner of war if it will be between the hands of the enemy.

His actions are infractions to the principles of civilized and criminal states and they require criminal accountability, despite all these, the demand is increasing for the use of mercenaries in international conflicts or civil wars, recently, another image appeared for mercenary in the military companies and private security that reality has proven its involvement in such activities, so must the international community should looms therefore with making an effective international system of monitoring and accountability.

$$
\text { (ج) جامعة الإخوة منتوري قسنطينة1،الجزائر2016 }
$$


صفوف جيوشها يدعون بالمرتزقة لخوض غمار الحرب حيث يشاركون مشاركة فعلية ومباثرة في

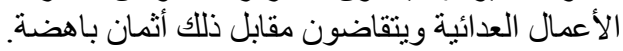

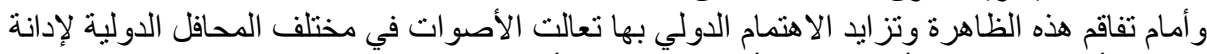

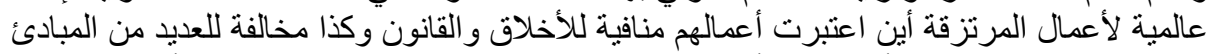

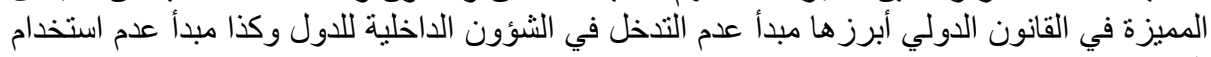

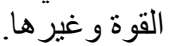

وللمرتزقة دور كبير ومؤثر في النزاعات الدولية وغير الدولية حيث لا يقتصر دورها لإنى على ترجيح

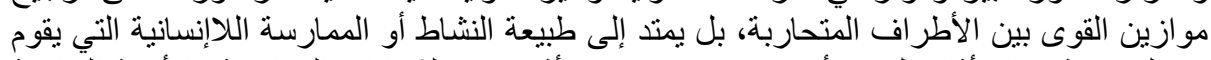

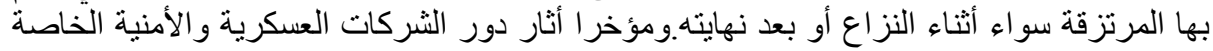

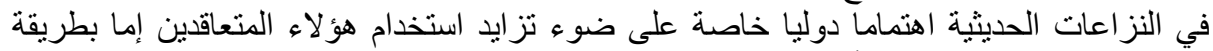

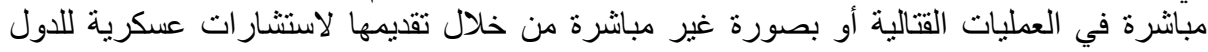

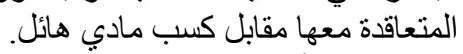

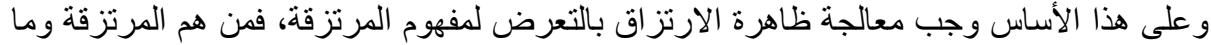

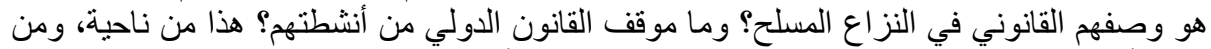

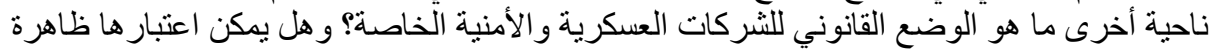

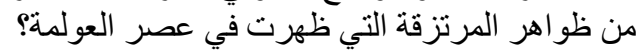

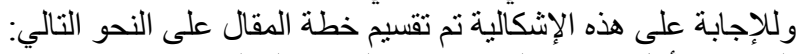

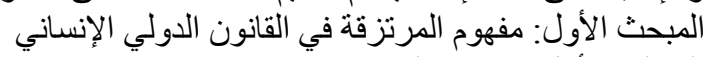

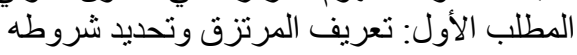

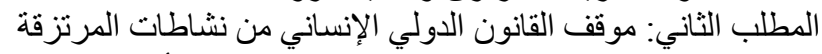

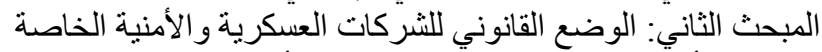

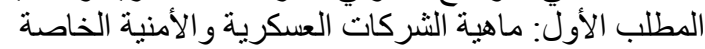
المطلب الثاني: الجهود الدولية في مجال تنظيم عمل الثركات الثية العسكرية والأمنية الخاصة

\section{مفهوم المرتزقة في القانون الدولي الإنساني}

المبحث الأول

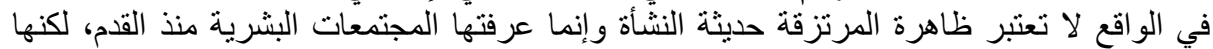

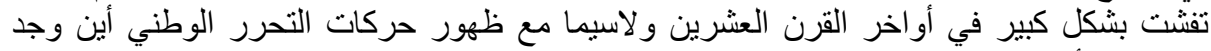

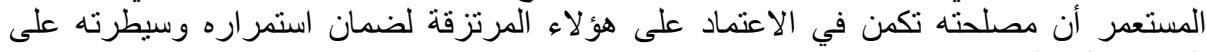

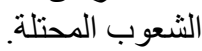

فأصبح حينئذ الارتزاق مهنة احترافية استقطبت الملايين من الطامحين بالثروات والثئ والمغامرين وكذا

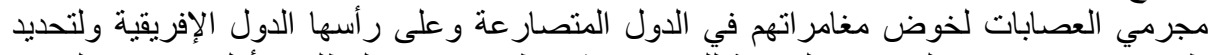

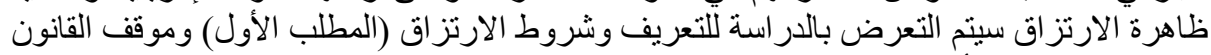
الدولي الإنساني من أنثطته (المطلب الثاني) فيما يلي: للإني المطلب الأول الميل

\section{تعريف المرتزق وتحديد شروطه}

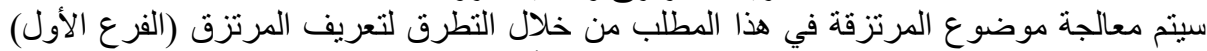
وتحديد شروط الارتزاق في ظل البرونوكول في الإضافي الأول لعام 1977 (الفرع الثناني) كمايلي:

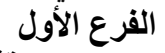

تعريف المرتزقة

لقد مر تعريف المرتزقة بعدة محاولات فبل تعريفه في البروتوكول الإضافي لعام 1977 الملحق 
باتفاقيات جنيف الأربعة لعام 1949، فقد كانت هناك محاولات إقليمية وأخرى دولية أسفرت على إلى

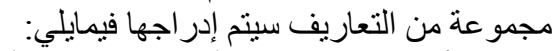

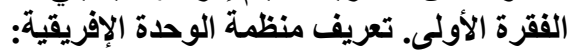

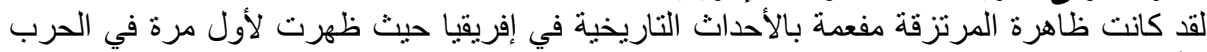

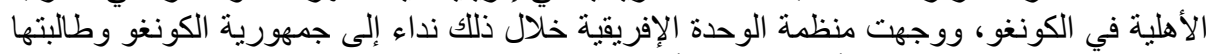

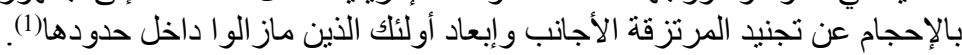

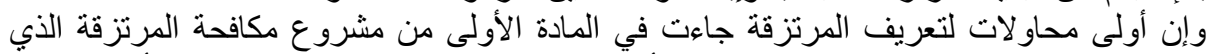

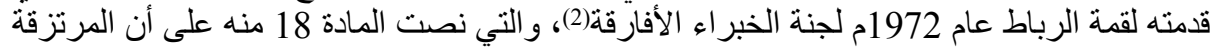

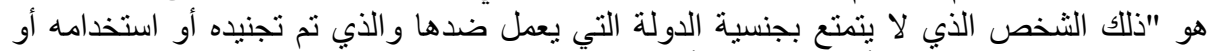

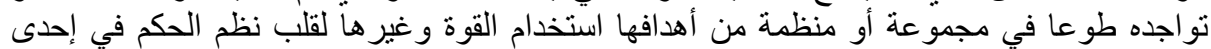

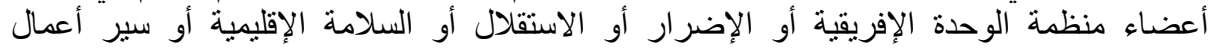

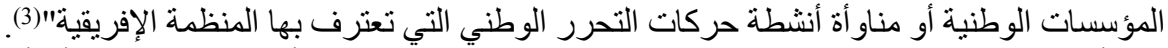

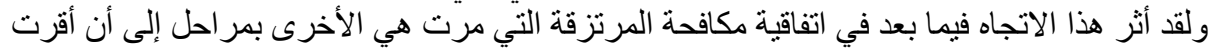

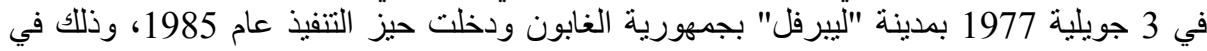
إطار منظمة الوحدة الإفريقية حيث جاء تعريفها شبيها تماما في صباغتها لإنها للتعريف الوارد في في في

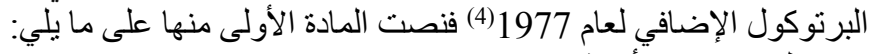

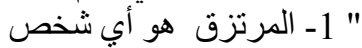

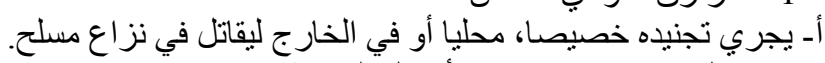
بـ يشارك فعلا ومباشرة في الأعمال العدائية.

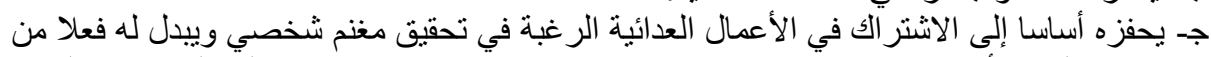

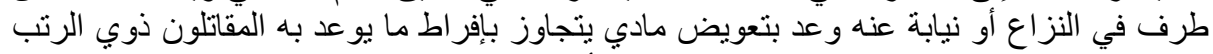

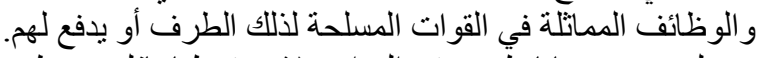

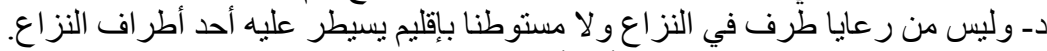

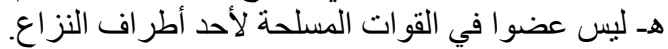
و - ليس موفدا في مهمة رسمية من قبل دولة ليست طرفا في النزاع بوصفه عضوا في قو اتها

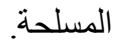

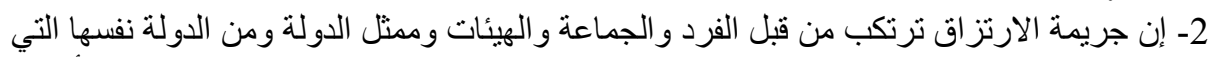

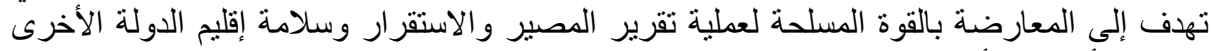

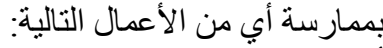
أــ التنظيم وُ التمويل و الإمداد و التنسليح و التندريب و التشجيع والدعم أو بأي سلوك لتوظيف عصابات

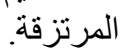
بـ التجنيد و التسجيل أو محاولة التسجيل في العصابات المذكورة.

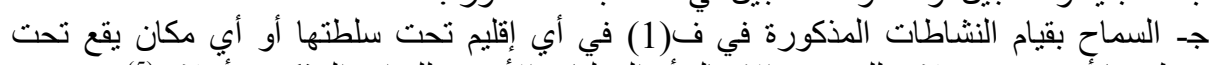

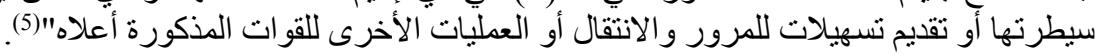

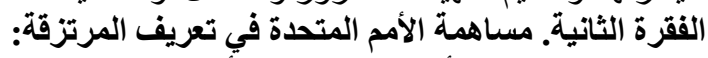

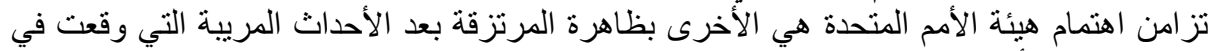

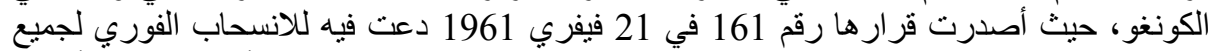

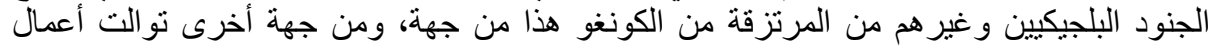

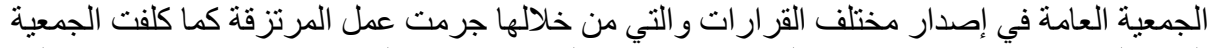
العامة لجنة خاصةً(6) عام 1980 لصياغة اتفاقية دولية ضد تجنيد المرتزقة و واستخدامهر وتحويلهر 
وقدمت مسودة بذللك عام 1989 ولم تختلف هذه الاتفاقية عن السياق الذي جاءت به كل من اتفاقية

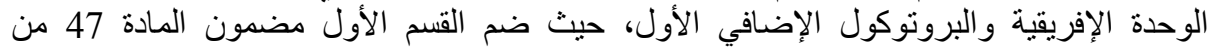

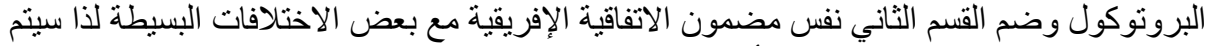

إدر اجرتط تعريف المرتزقة في هذا الأخير من هذه الاتفاقية كما يلي: الإني

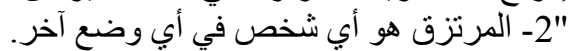

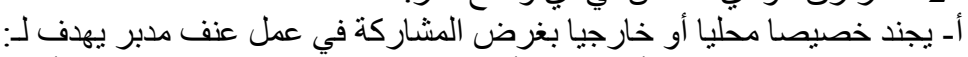

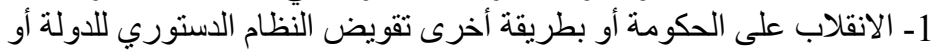

2- 2ق تقويض السلامة الإقليمية للاولة.

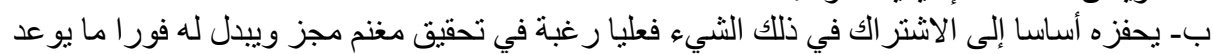

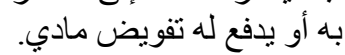

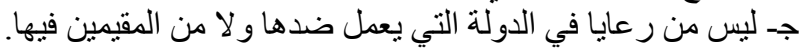

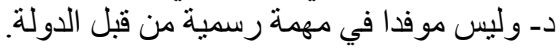

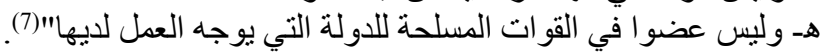

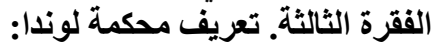

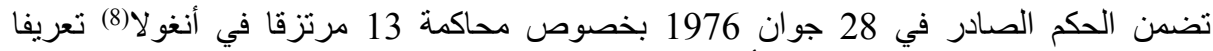

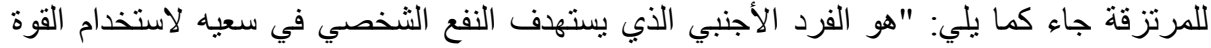
لعرقلة حركة الثعب الهادفة إلى تقرير مصبره والذب الذي يعمل بذلك لفرض مخططات الاستعمار

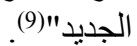

الفقرة الرابعة. تعريف لجنة التحقيق الدولية:

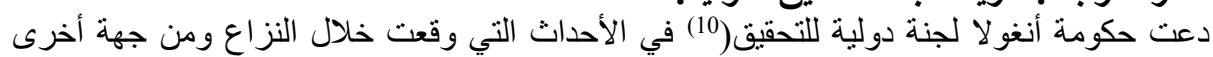

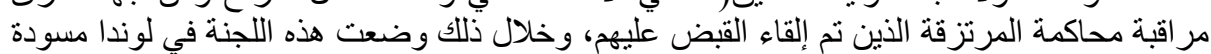

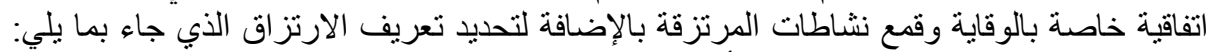

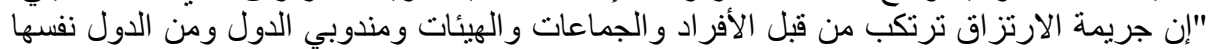

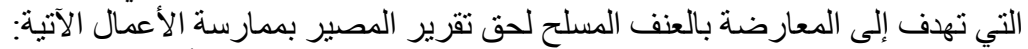

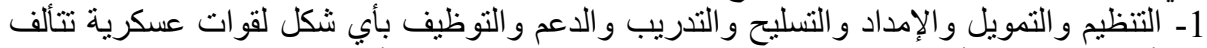

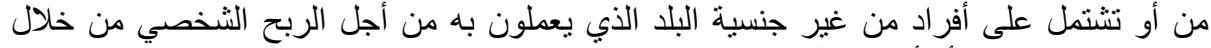
الحصول على مرتب أو أي نوع آخر من آلتير جن التعريف المادي.

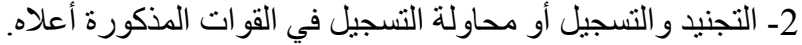

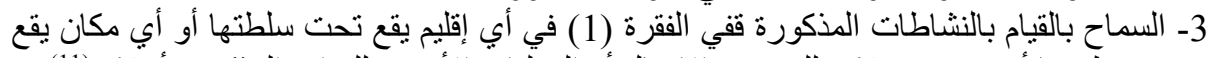

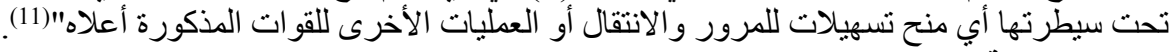
الفقرة الخامسة. تُعريف جنيف:

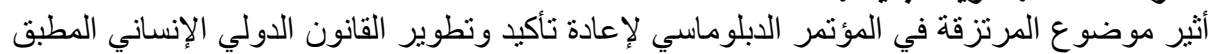

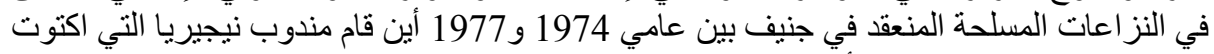

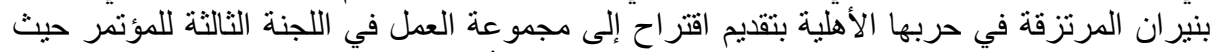

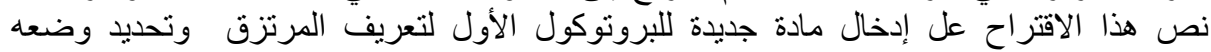
القانونى (12). واستمرت فعلا مناقتشة هذا الاقتر اح الذي لقي ترحيبا كبير ا من قبل الدول أثناء الدورة الرابعة للمؤتمر

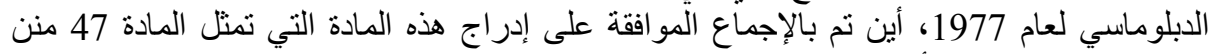

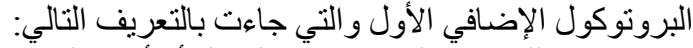

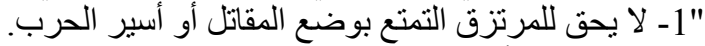

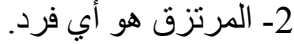


أـ يجري تجنيده خصيصا، محليا أو في الخارج ليقاتل في نزاع مسلح. بـ بشارك فعلا ومباشرة في الأعمال العدائية.

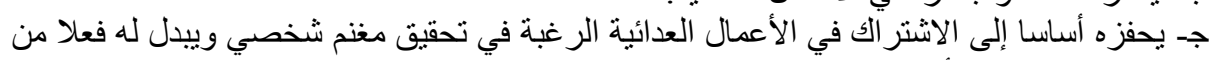

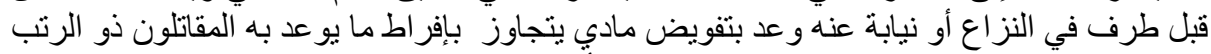

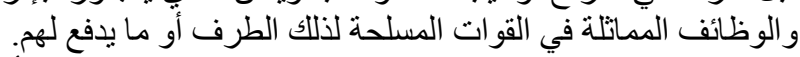

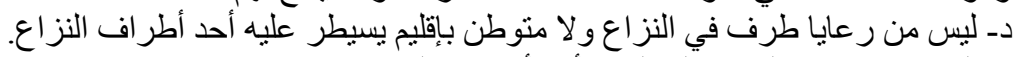

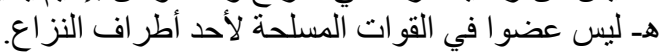
و - وليس موفدا في مهمة رسمية من قبل دولة ليست طرفا في النزاع بوصفه عضوا في قواتها

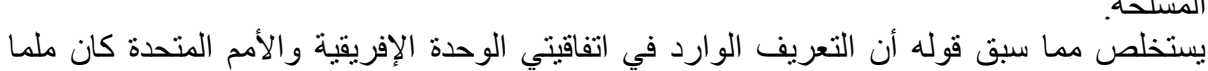

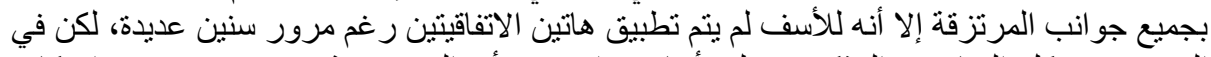

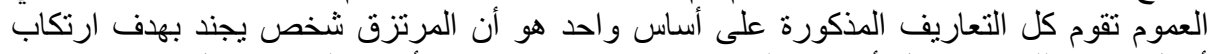

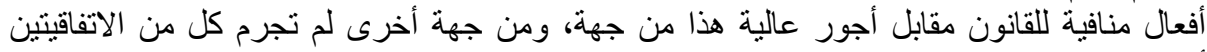

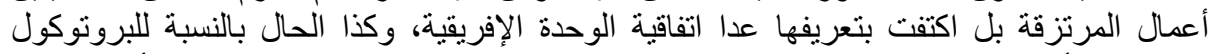

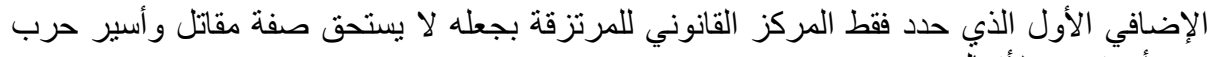

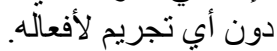

$$
\text { الفرع الثاني }
$$

\section{شروط المرتزقة في ظل البروتوكول الإضئي الإفي الأول:}

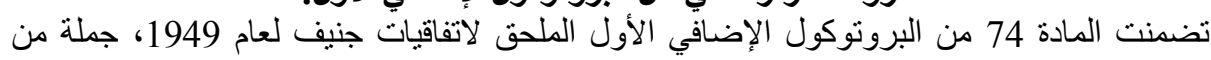

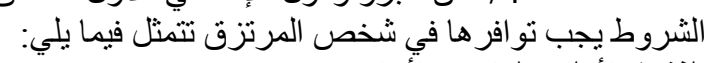

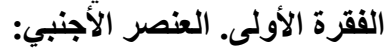

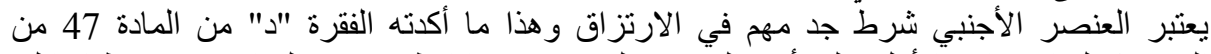

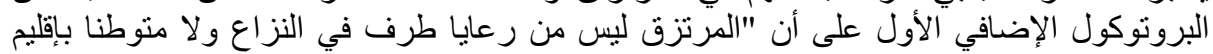

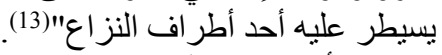

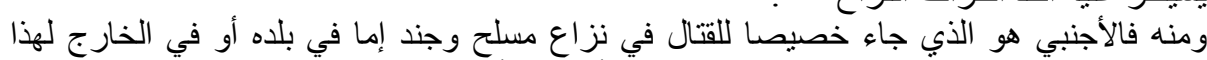
الغرض، ولم يكن مقيماً في البلد الذي يعمل لحسابه أو ضده أو مقيما في إقليم تحت سيطرنه. 


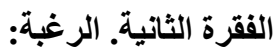

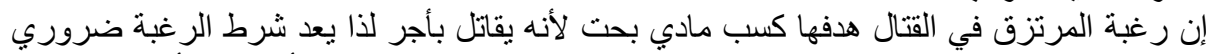

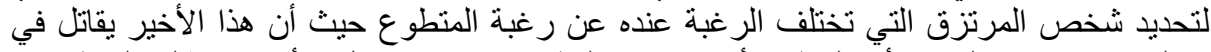

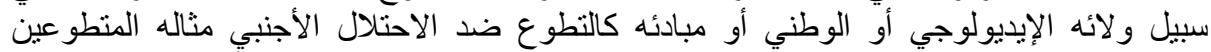

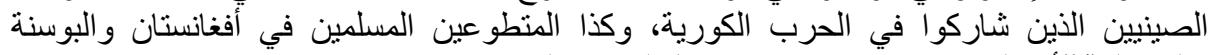

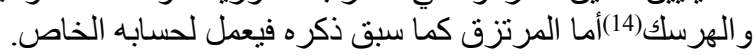

الفقرة الثالثة. الحافز: المتزف

نصت المادة الفرعية (ج)/2) من المادة 47 من البروتوكول الإضافي الأول فيما يتعلق بالحافز "يحفزه

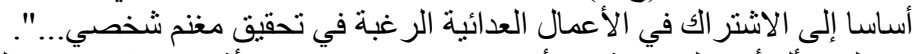

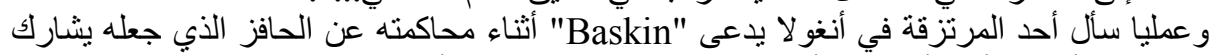

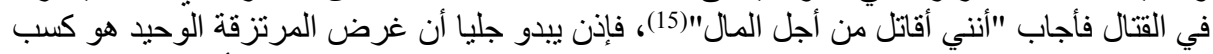

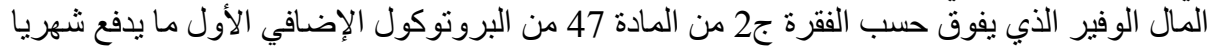

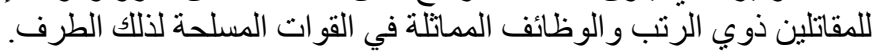

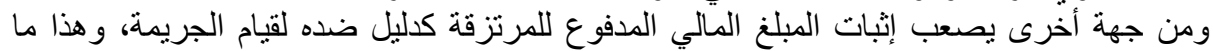

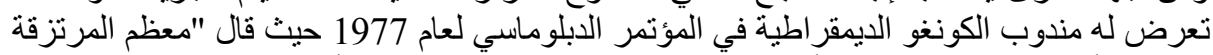

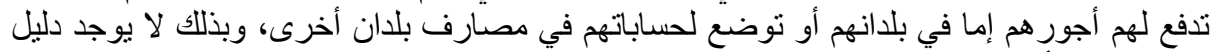

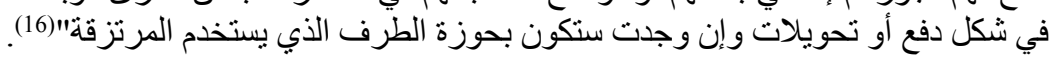

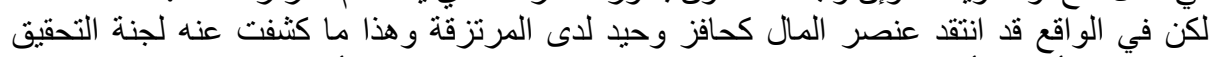

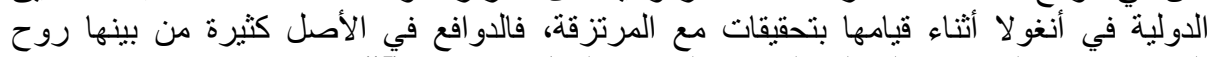

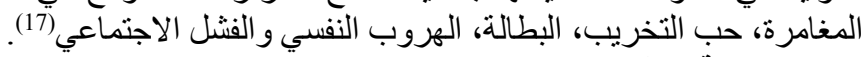

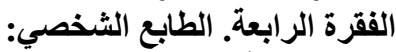

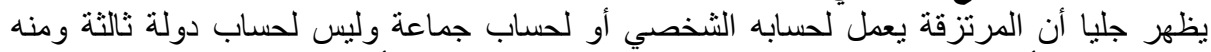

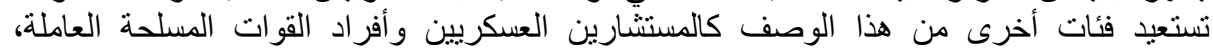

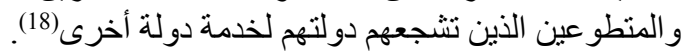

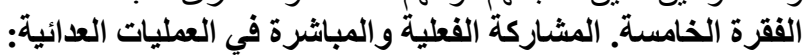

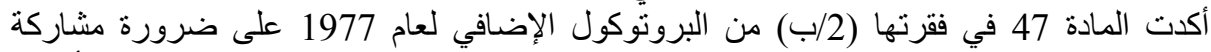

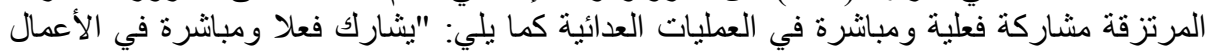

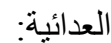

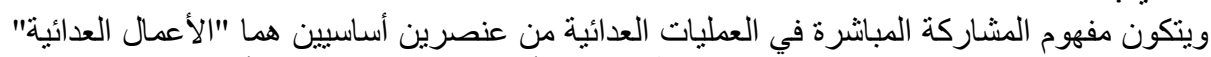

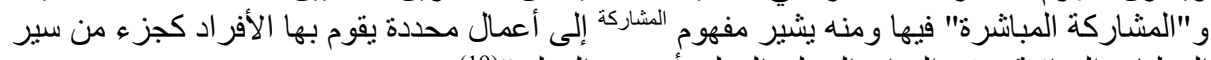

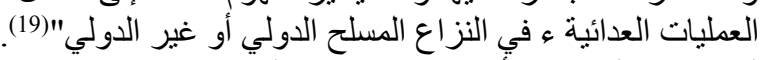

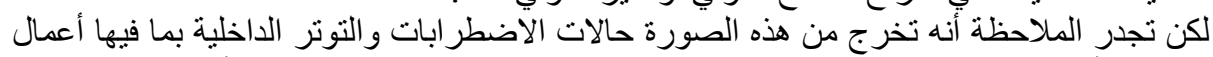

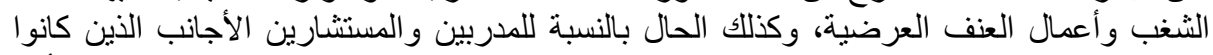

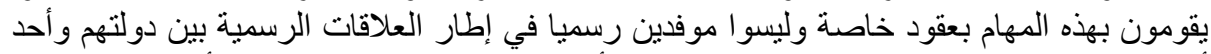

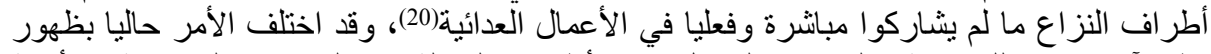

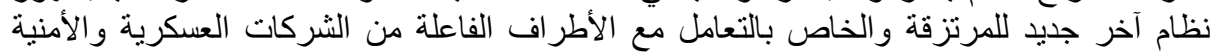

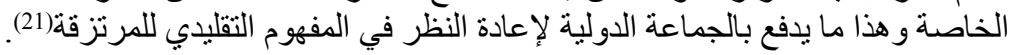

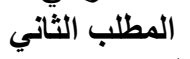

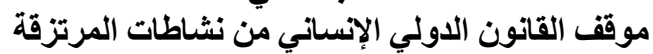

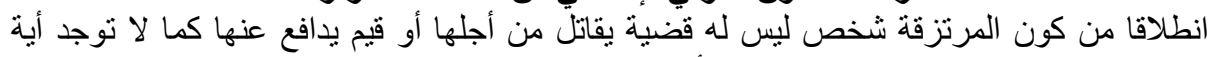

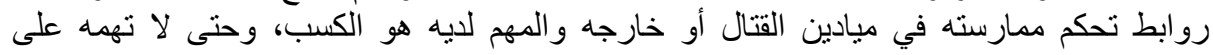




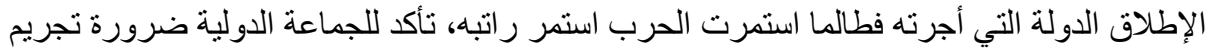

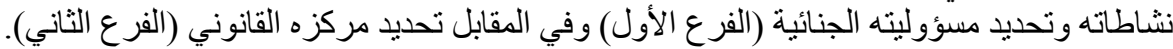

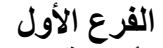

\section{تجريم أنثطة المرتزقة المبرة}

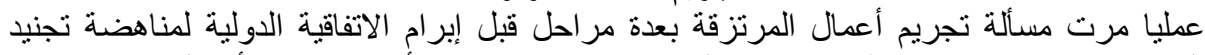

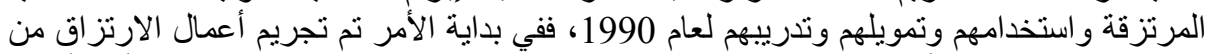

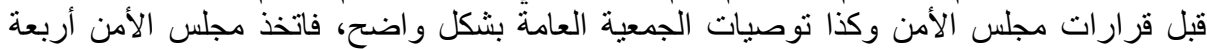

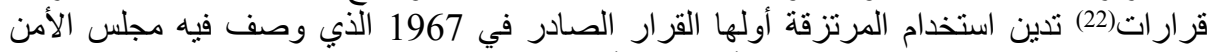

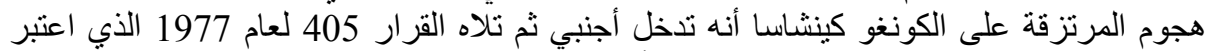

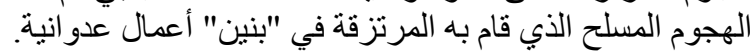

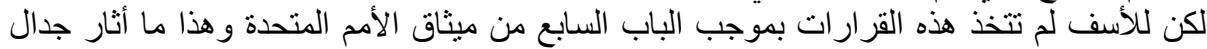

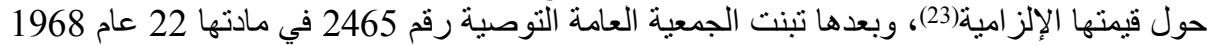

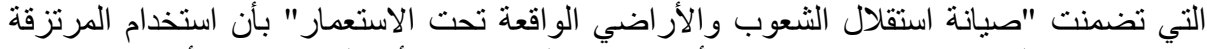

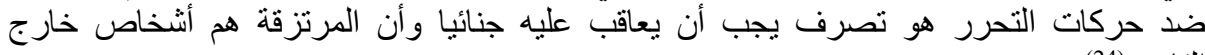

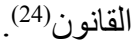
أضف لذلك لقد حرمت الفقرة الخامسة من التوصية رقم 3103 استخدام المرتزقة من قبل الأنظمة

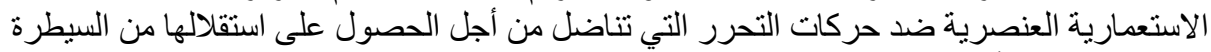

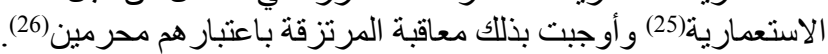

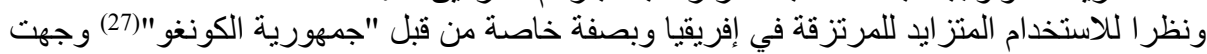

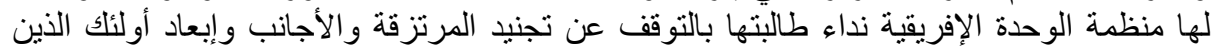

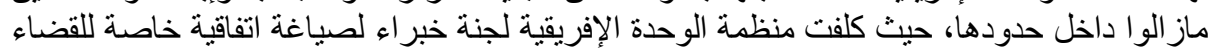
على ظاهرة الارتزاق في إفريقيا.

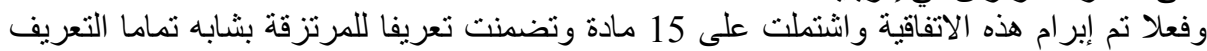

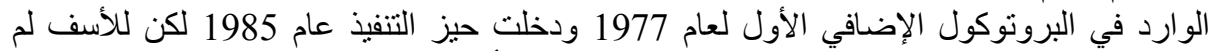

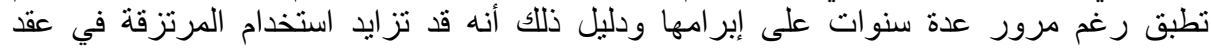

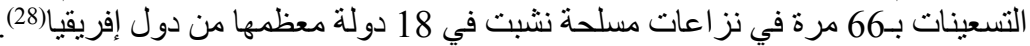

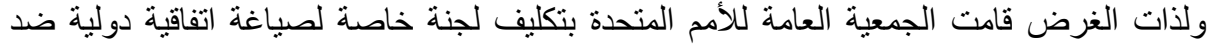

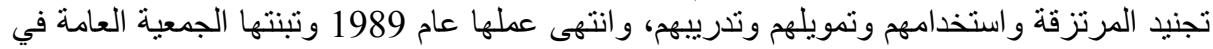

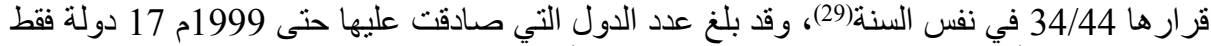

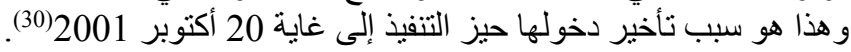

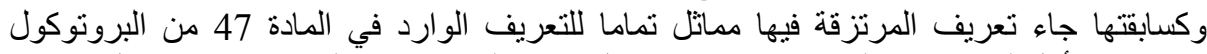

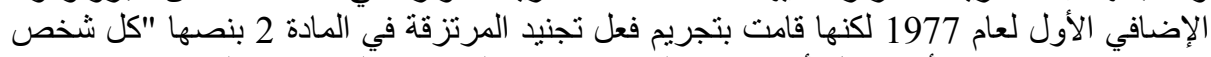

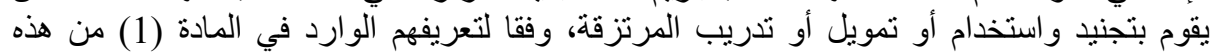
الاتفاقية برتكب جريمة في حكم هذه الاتفاقية".

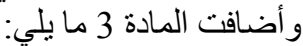

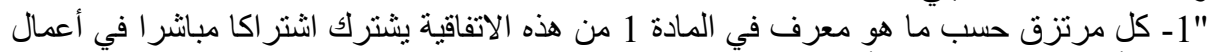

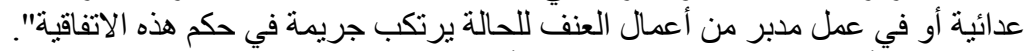

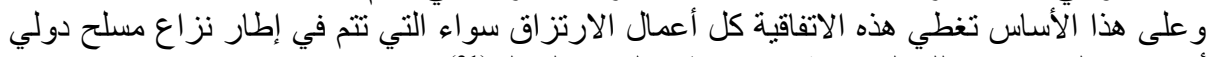

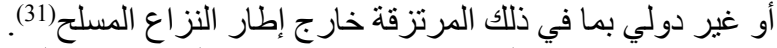
ومنه فاحتر افت مهنة المرتزقة يقع خارج دائرة الثرار الثرعية في القانون الدولي فهي جريمة دولية خطيرة ذات اختصاص عالمي وكذا الحال بالنسبة لاستخدامهم وتدرييهم، وأما في إطار المساءلة الجنائية 
فعمليا أتيحت الفرصة للححاكم الإفريقية للنظر في نشاطات المرتزقة فأصدرت محكمة أمن الدولة

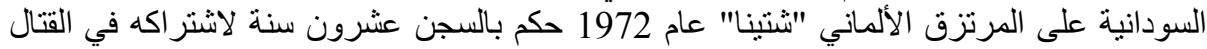

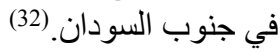

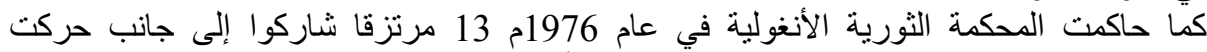
"UNITA"

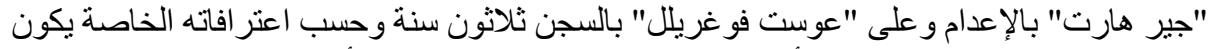

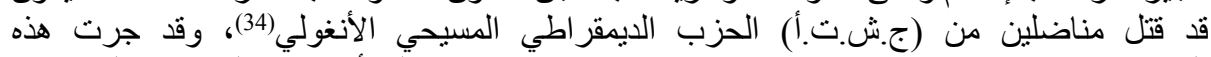

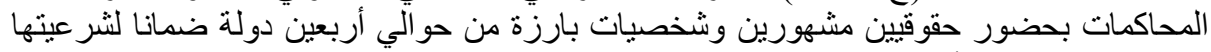

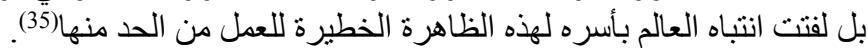

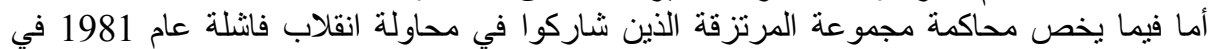

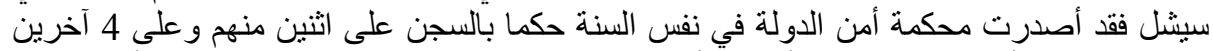

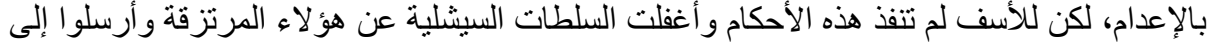
جنوب إفريقيا(36).

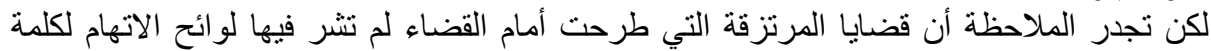

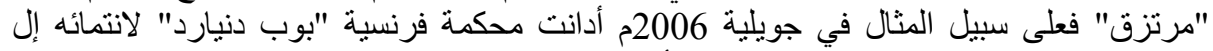

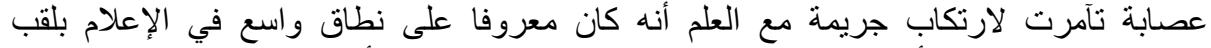

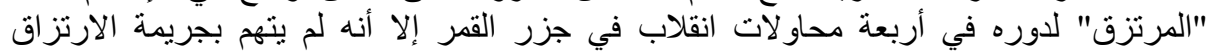

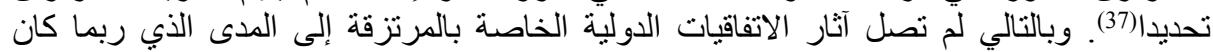
متوقعا لها أصلا. ويوجد إلى جانب اتفاقية الأمم المتحدة أيضا مشروع قانون لجنانة القانون الدولي لعام 1991 في لجي

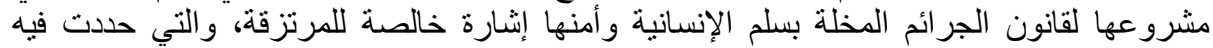

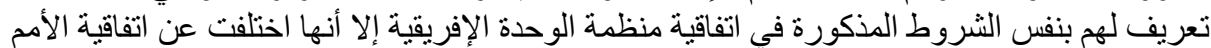

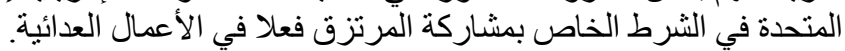

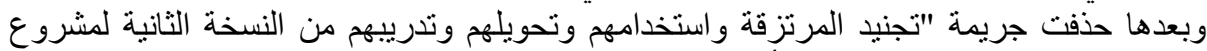

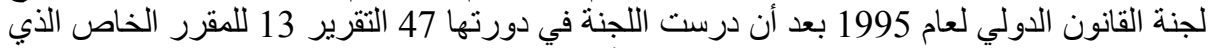

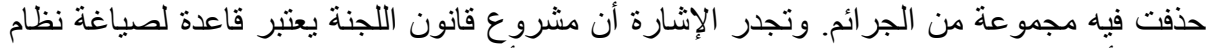

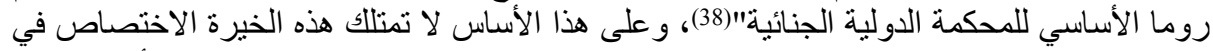

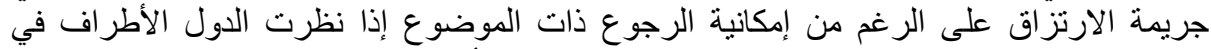

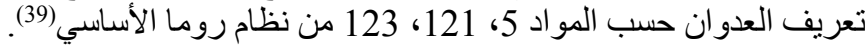

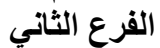

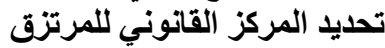

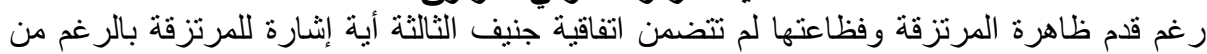

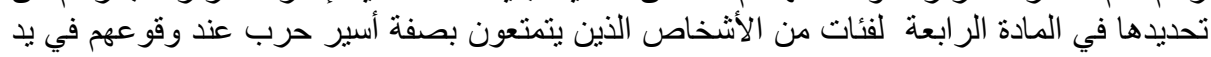

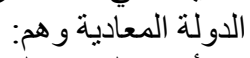

1- أفر اد القوات المسلحة لأحد أطر اف النزاع، و المليشيات أو الوحدات المتطوعة التي تشكل جزءا

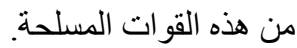
2- أفراد المليشيات الأخرى والوحدات المتطوعة الأخرى، بمن فيهم أعضاء حركات المقاومة

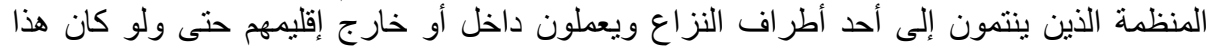
الإقليم ممثلا بما فيها حركات المقاو المة المنظمة المنظمة المذكورة.

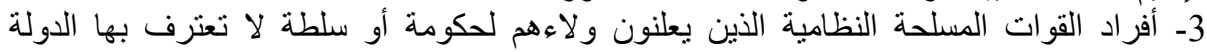


4ـ الأشخاص الذين بر افقون القو ات المسلحة دون أن يكونو ا في الو اقع جز عا منها...

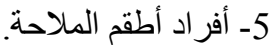

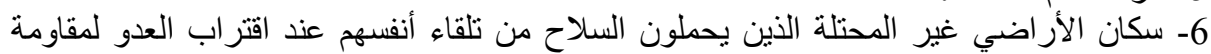

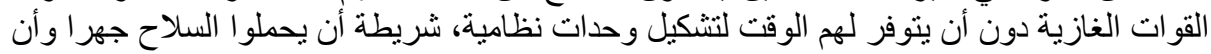

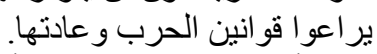

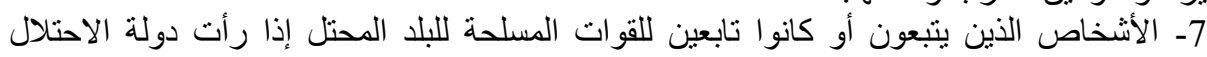
ضرورة اعتقالهم بسبب هذا الانتماء... . 8- الأشخاص الذين ينتمون إلى إحدى الفئات المبينة في هذه المادية الذين تستقبلهم دولة محايدة أو غير

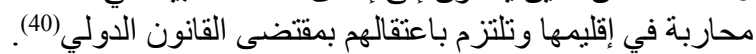

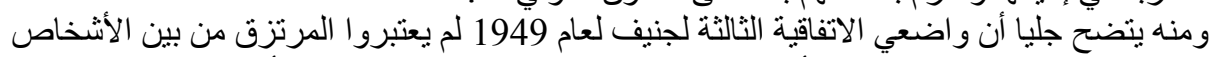

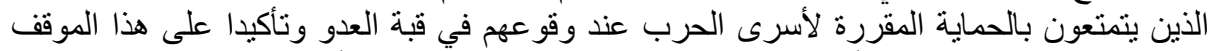

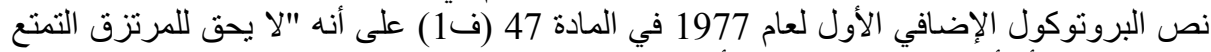

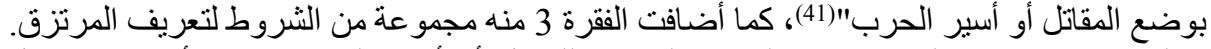

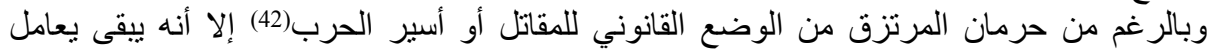

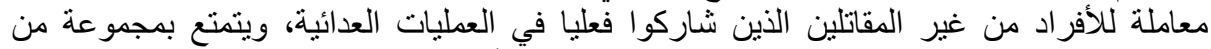

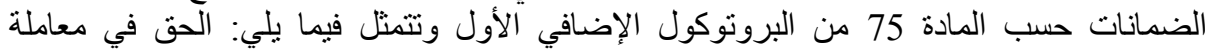

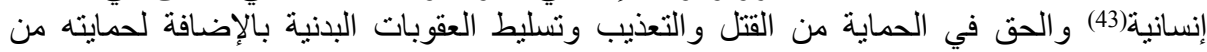

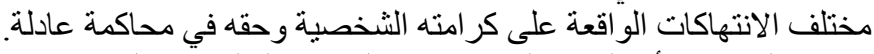

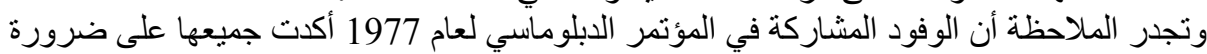

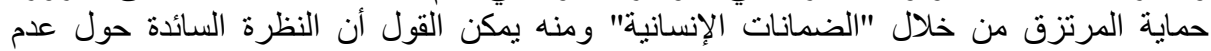

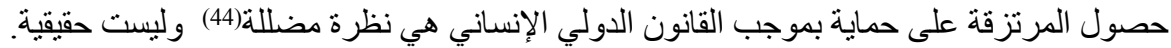

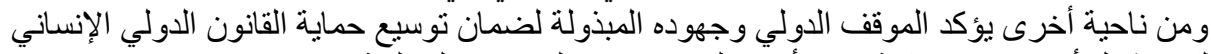

لكي يشمل أوسع فئات ممكنة من الأفراد المنو اجدة في النزاعات المبات المسلحة. المبحث الثاني

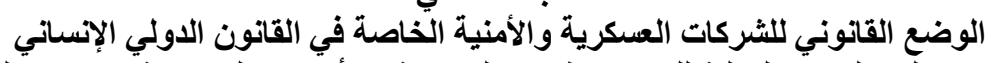

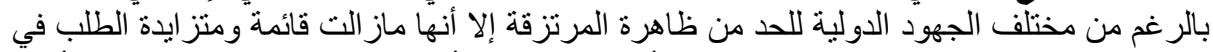

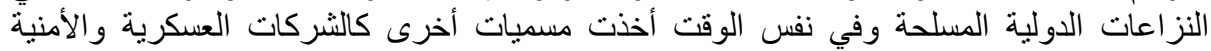

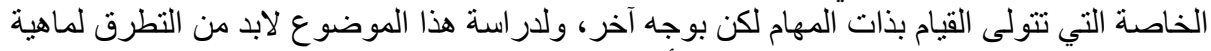

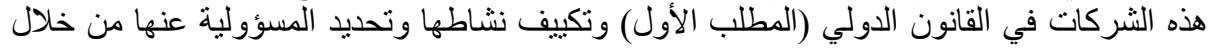

مختلف الجهود الدولية (المطلب الثاني). 


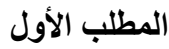

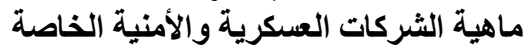

إنه في ضوء نهوض الصناعة العسكرية الخاصة أصبح من الضرورية الضانية تحديد مفهوم هذه الثركات ومجال عملها وهذا من خلال الفر عين التاليين:

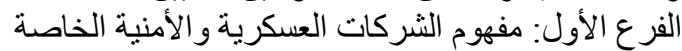

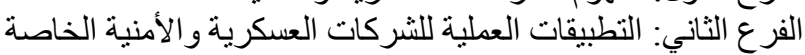

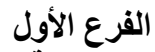

\section{مفهوم الثركات العسكرية والأمنية الخاصة}

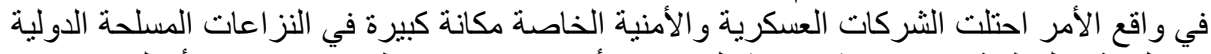

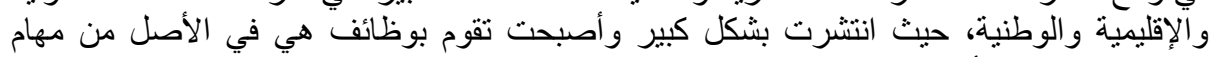

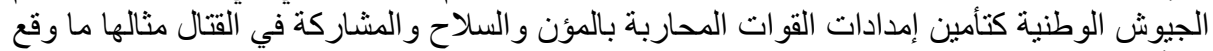
في أفغانستان و العر اق و وغير هانيا (45).

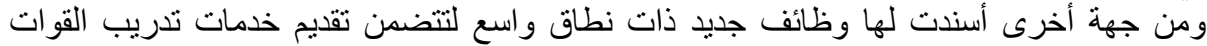

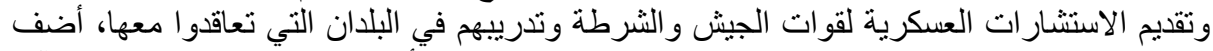

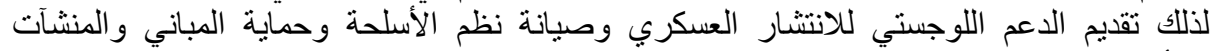

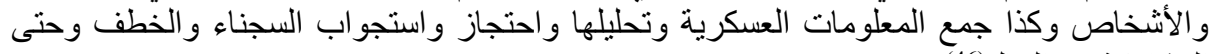

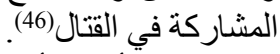

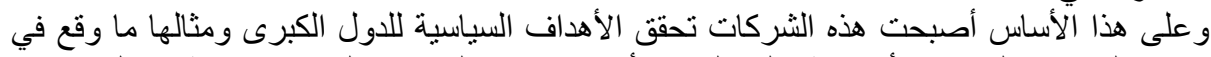

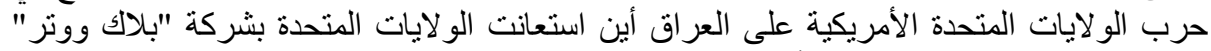

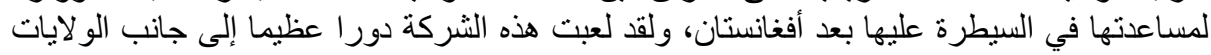

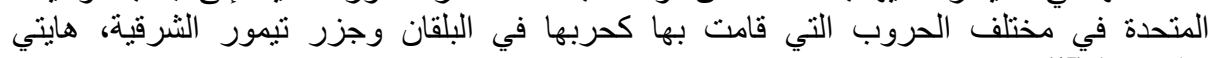

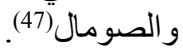

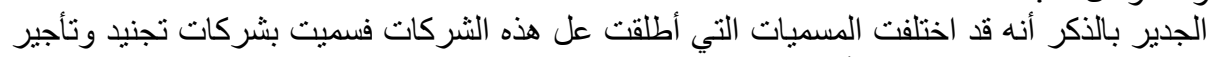

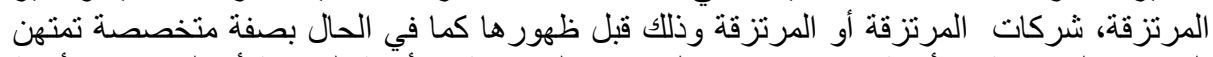

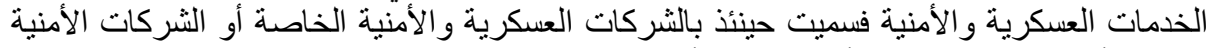

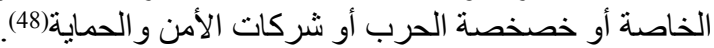

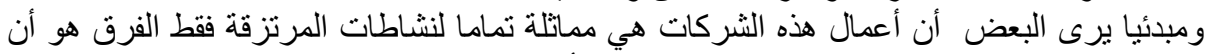

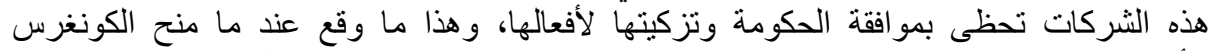

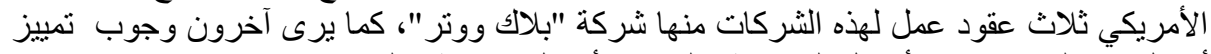

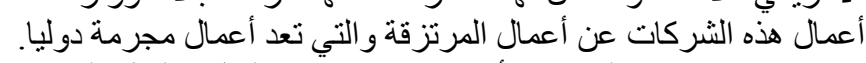

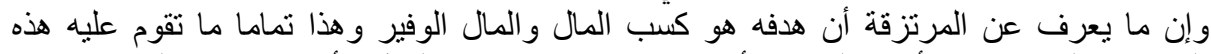

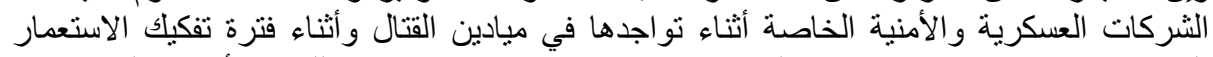

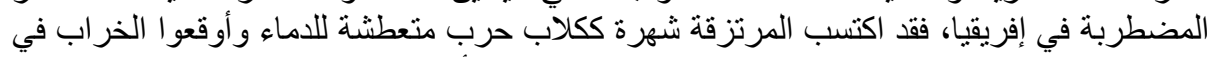

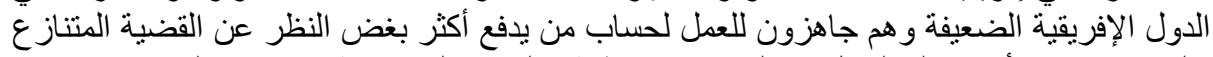

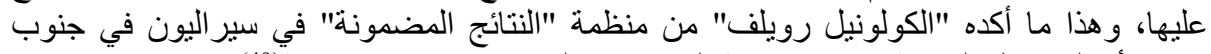

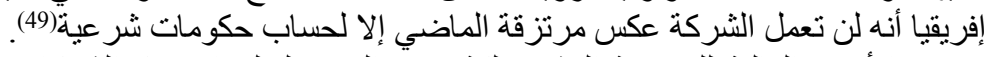

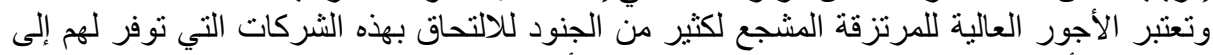

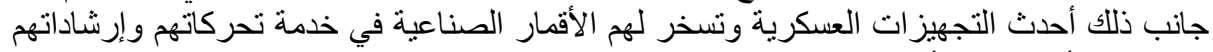

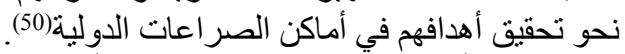

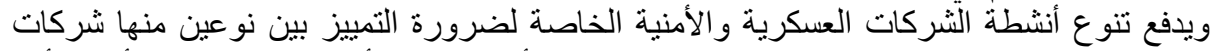
عسكرية خاصة يقترب مفهومها من المرتزقة وشركات الأنية أمنية خاصة أخرى فقد عرفت الأولى بأنها 


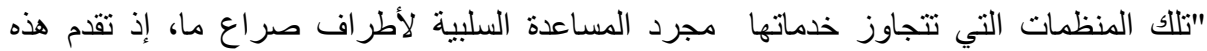

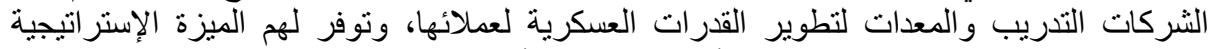

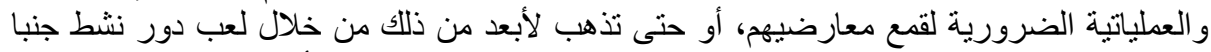

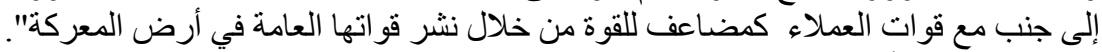

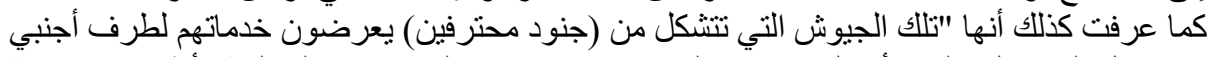

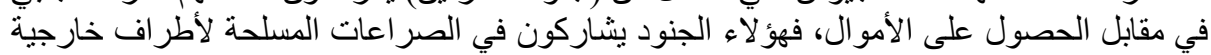

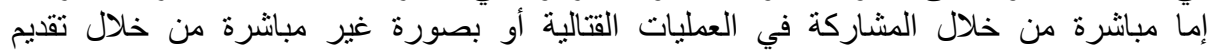

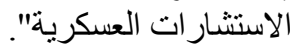

ومن جهة أخرى عرفها مركز جنيف للرقابة الديمقر اطية على القوات المسلحة في 2006 بأنها "تمثل إعلى

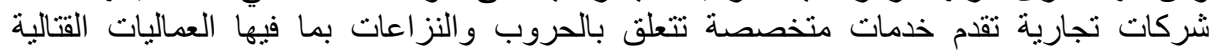

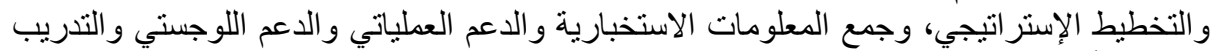

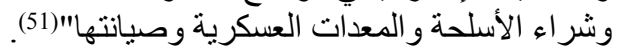

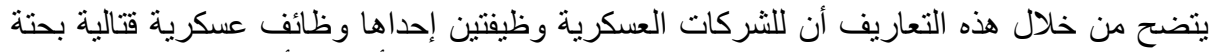

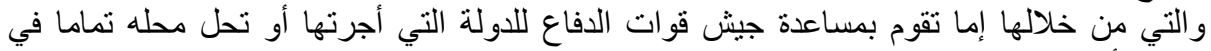

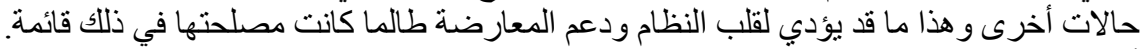

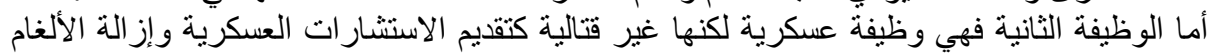

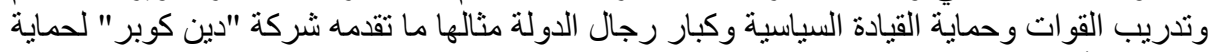

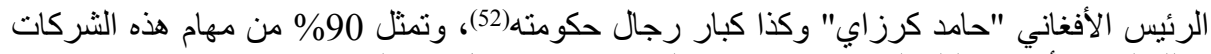

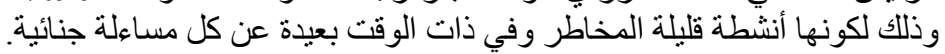

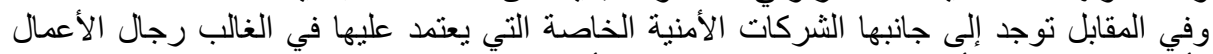

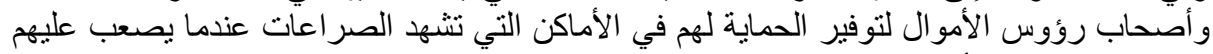
إيجادها عند قوات الأمن داخل دولتهم.

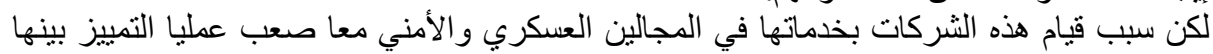

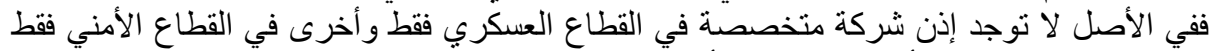

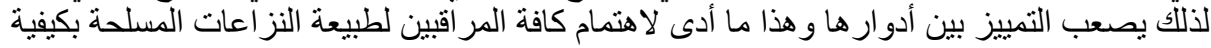

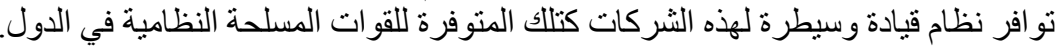

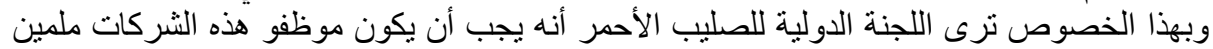

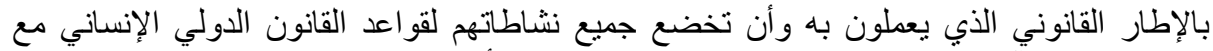

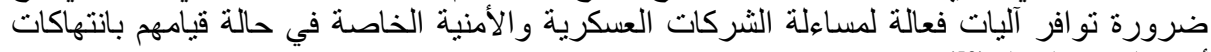
أنثاء النز اع المسلح (53). ويقع إذن الالتزام على هذه الثركات وكذا الدول المؤجرة والدول التي تكون الثركات العسكرية

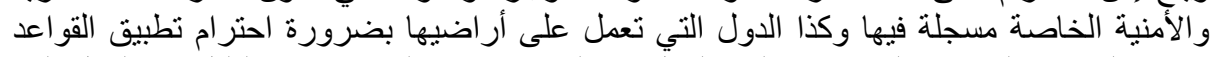

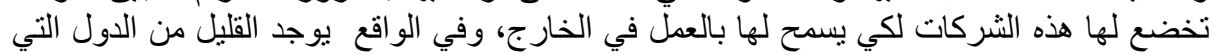

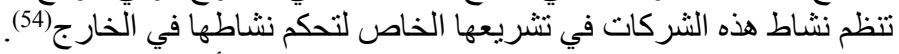

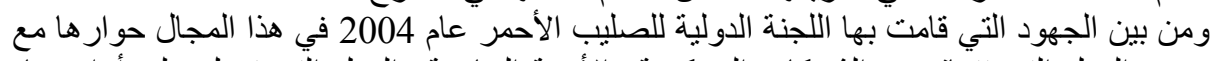

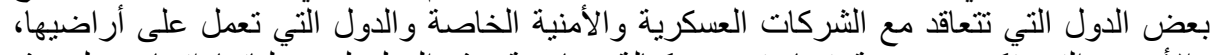

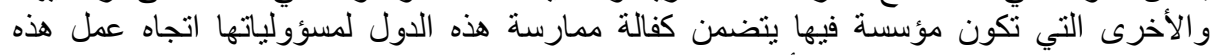

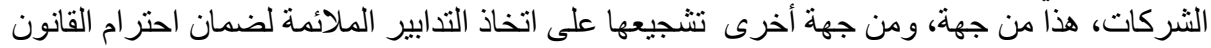

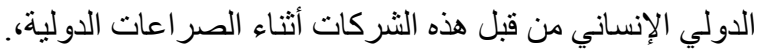

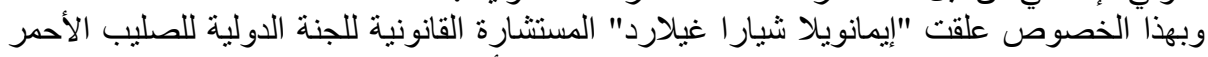
بالنسبة لمدى ملائمة قواعد القانون الدولي الإنساني لهذه الأنشطة قائلة: "إن القانون الدولئ الداني الإنساني الإني 


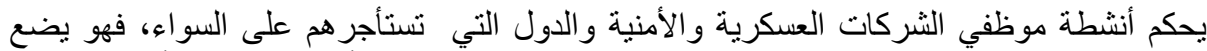

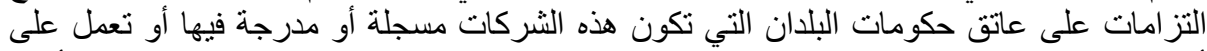

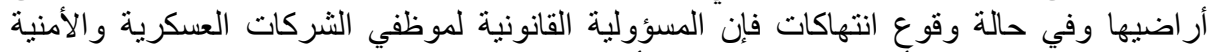

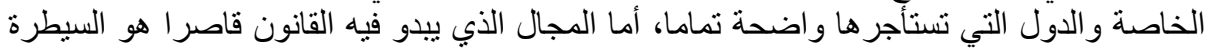

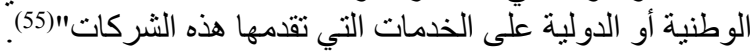

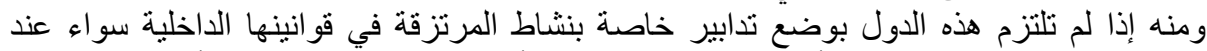

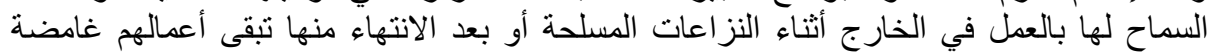

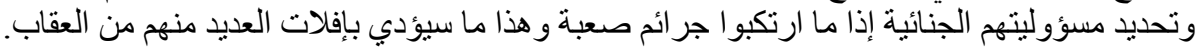

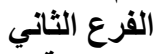

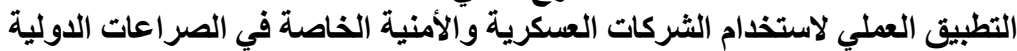

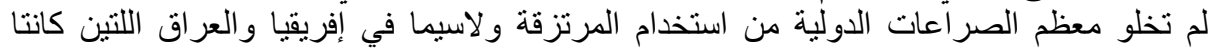

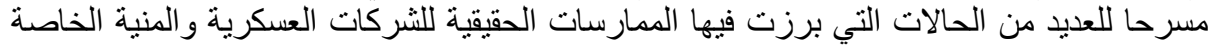

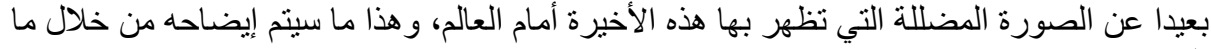

الفقرة الأولى. المرتزقة في إفريقيا:

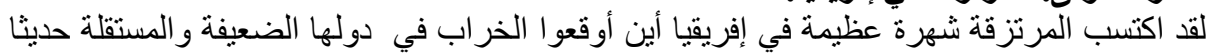

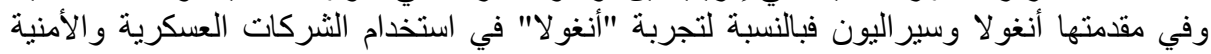

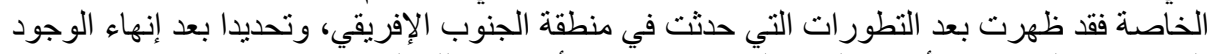

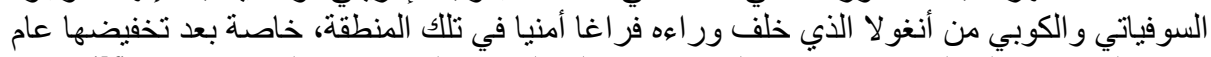

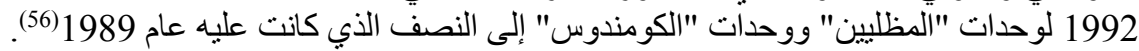

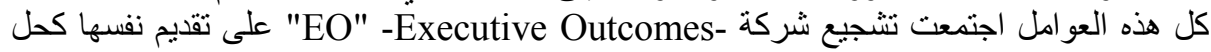

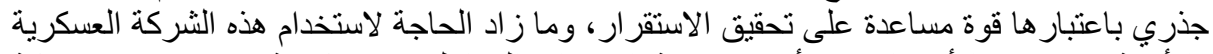

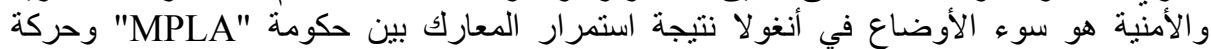

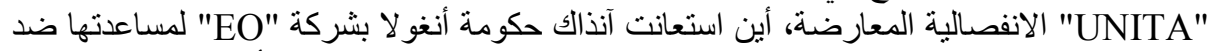

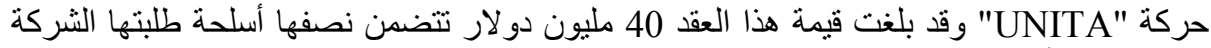

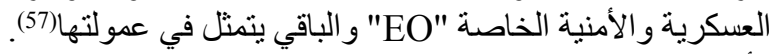

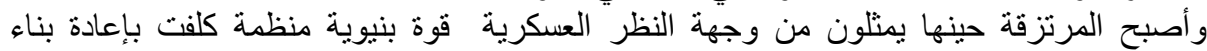

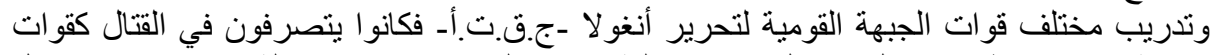

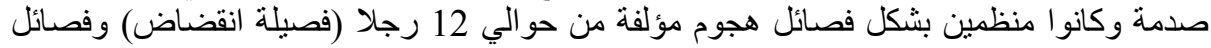

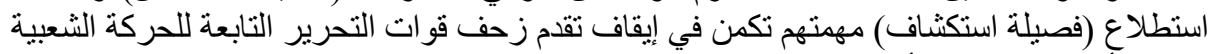

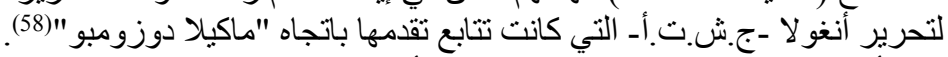

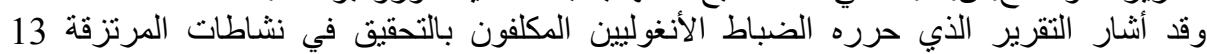

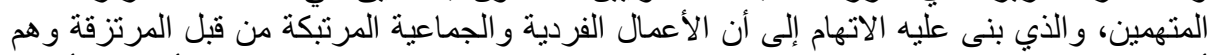

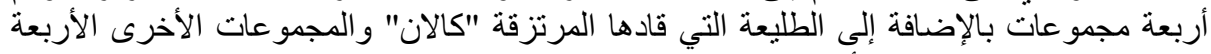

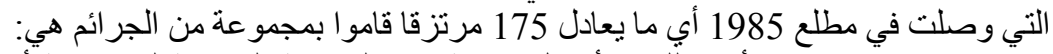

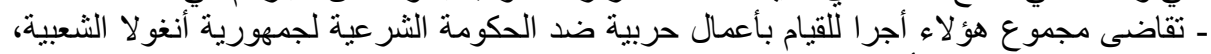

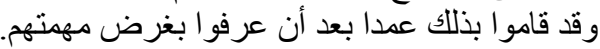

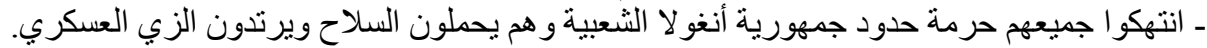

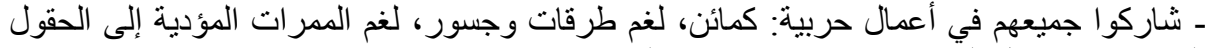

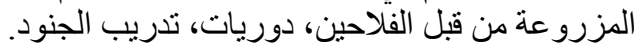
ـ قامو ا جميعهم بعمل قمعي ضد المدي، دوريات السكان(59). 
الفقرة الثانية. المرتزقة في العراق:

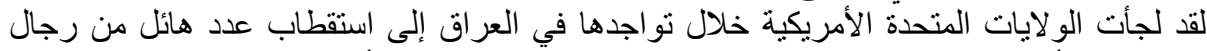

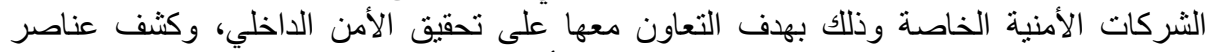

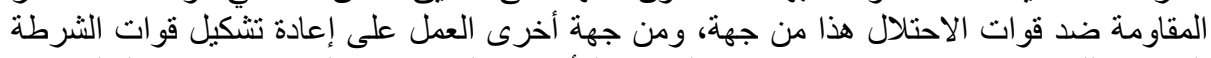
العراقية للقيام بمهامها في إطار توفير الحماية للأفراد والمؤسسات السياسية، والعادية وكذا الدبلوماسية

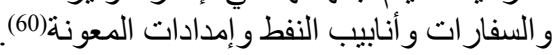

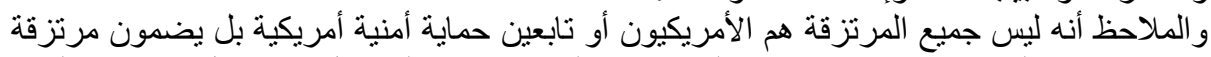

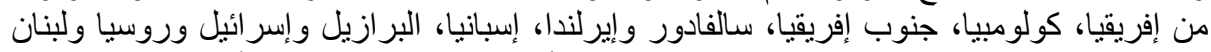

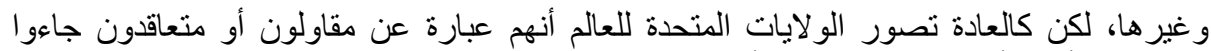

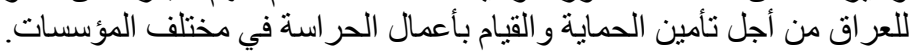

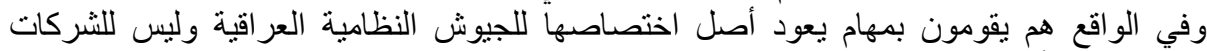

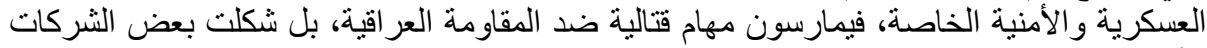

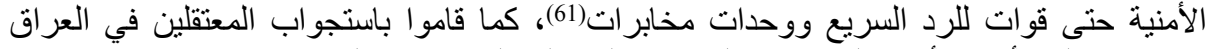

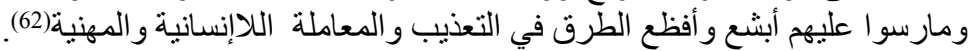

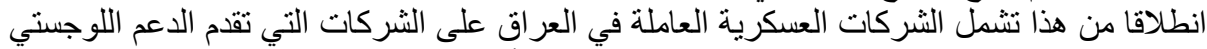

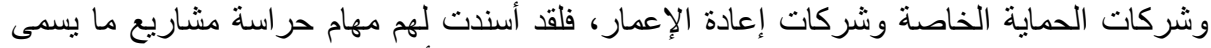

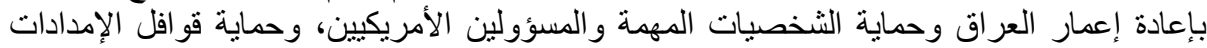

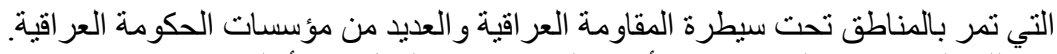

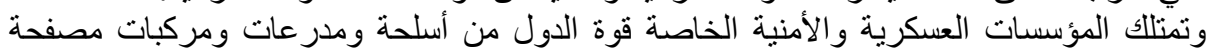

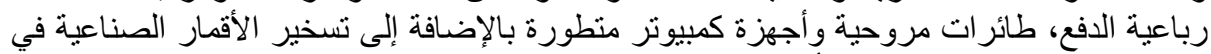

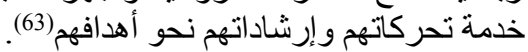
وتعتبر شركة "بلاك ووتر" من وأفرى أقوى الثركات العسكرية والأمنية الخاصة حيث يمكنها أن تنشر

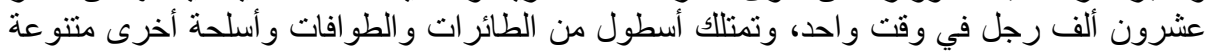

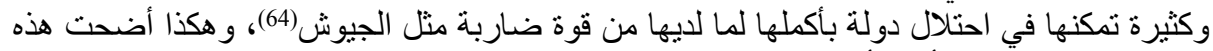

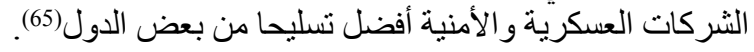




\section{المطلب الثاني - اني \\ الجهود الدولية في مجال تنظيم عمل الثركات العسكرية والأمنية الخاصة الثانية}

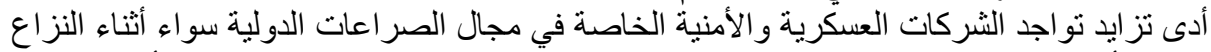

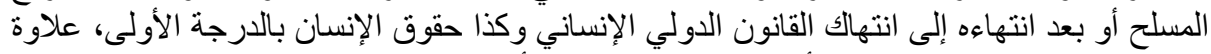

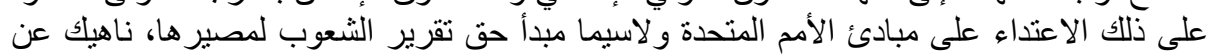

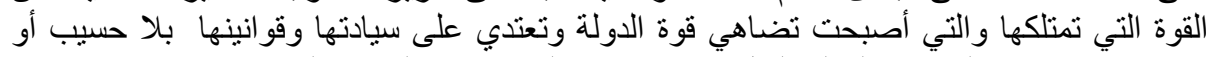

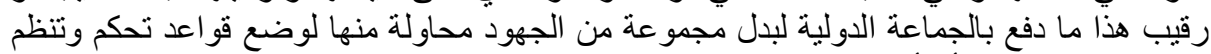

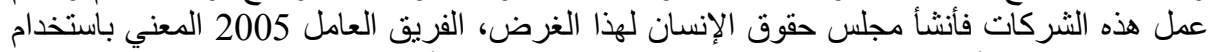

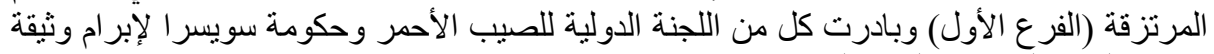

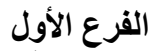

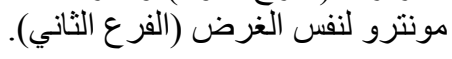

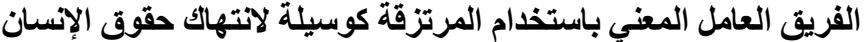

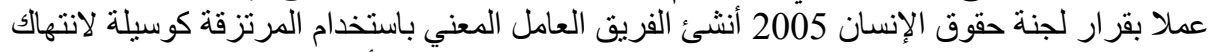

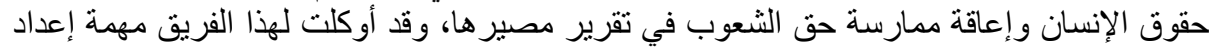

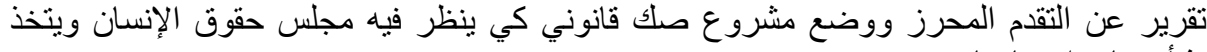

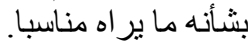

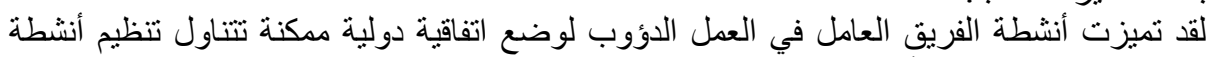

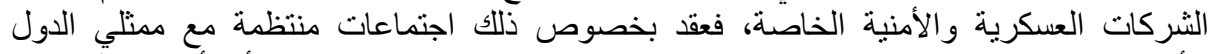

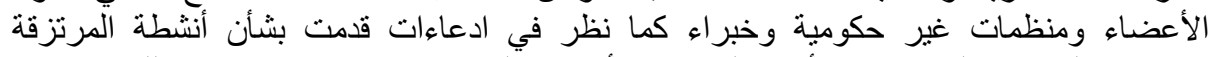

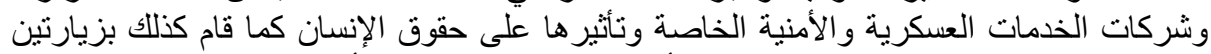

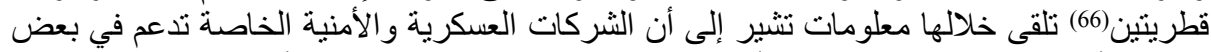

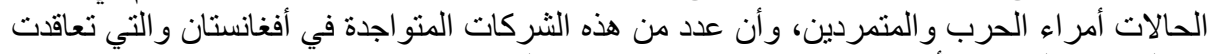

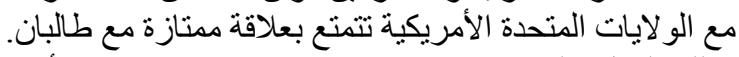

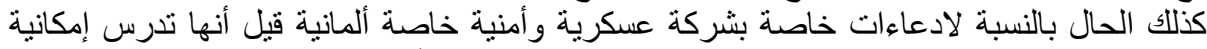

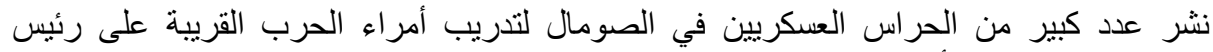
الصومال "عبد النور أحمد درمان" الذي نصب نفس فئ رئيسا لكنه في الواقع لا يحظى باعتر اف دولي

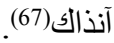

وللقيام بمهمته على أكمل وجه أرسل الفريق العامل 17 رسالة في المجموع إلى 15 بلدا تزعم فيها

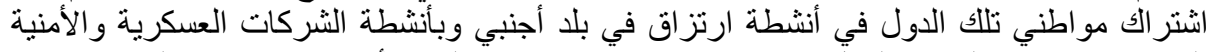

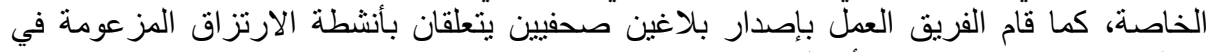

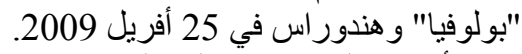

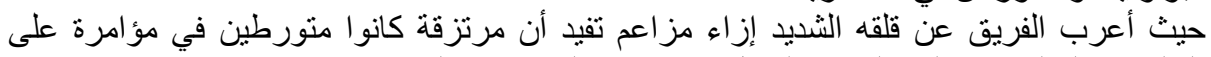

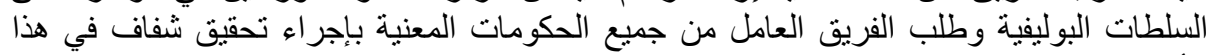

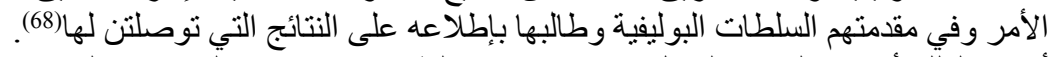

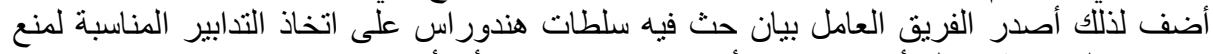

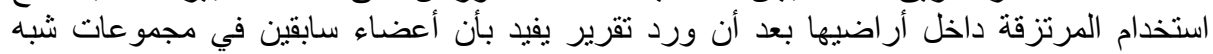
عسكرية من كولومبيا قد جندوا في هندو أندور اسن.

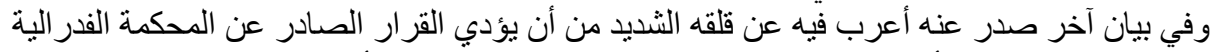

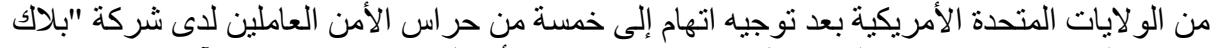

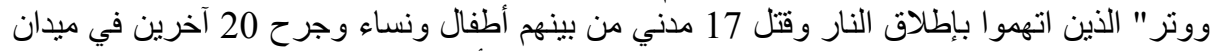

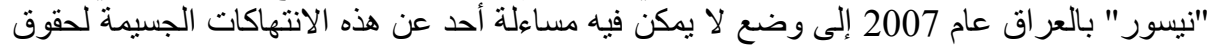


الإنسان ويطالب الفريق العامل الحكومة باتخاذ جميع الإجراءات المناسبة لعدم إفلات الجناة من (69) (69).

ناهيك عن هذا قام الفريق العامل بزيارتين قطريتين عام 2009 إلى كل من الو لايات المتحدة الأمريكية

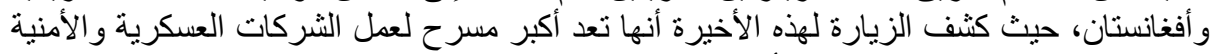

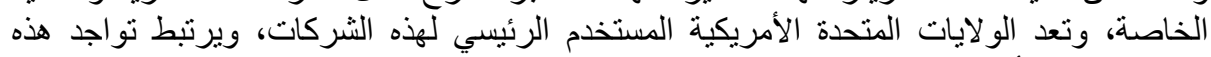

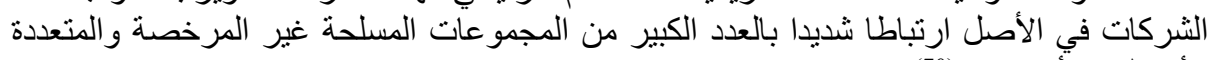
الأشكال في أفغانستان (70).

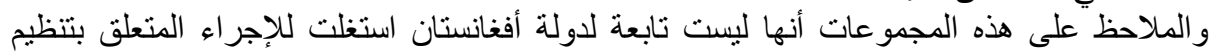

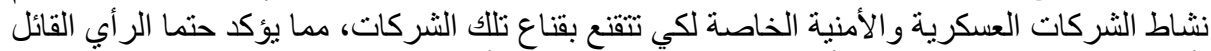

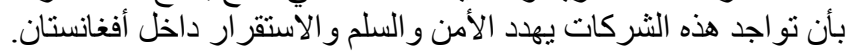

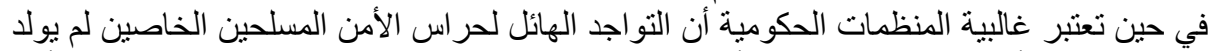

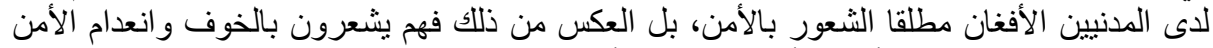

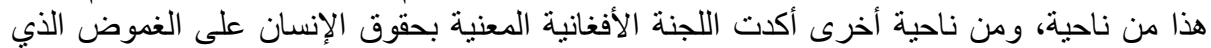
ينتاب اختصاص هذه الشركات في الأر اضي الأفغانستانية، وكذا بالنسبة للمساءلة النة الجنائية للعاملين فيها

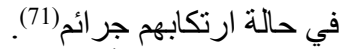
وفي نقطة ميدانية أخرى زارئ الفرانيق العامل الولايات المتحدة الأمريكية في 2009 أين تبين لايه أن

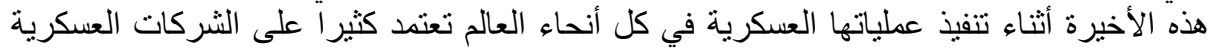

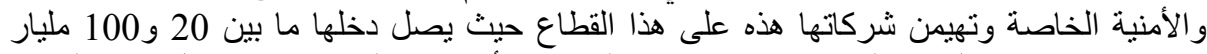

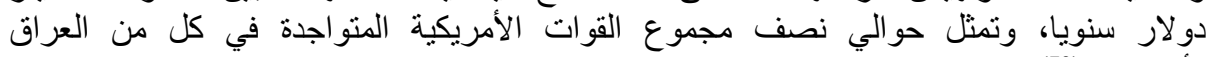
و وأفغانستان (72).

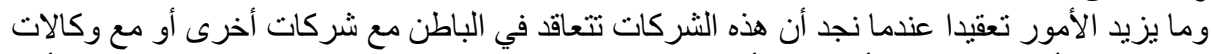

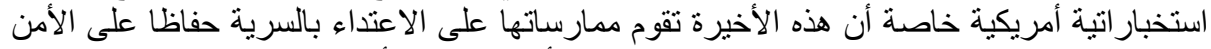

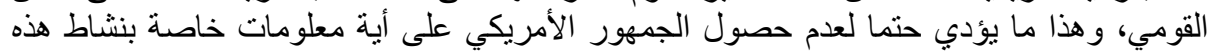

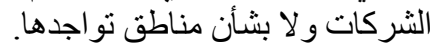

وبهذا الخصوص درس الفريق العامل مسألة الثركة الأمريكية المعروفة حاليا باسم " Xd Black Water

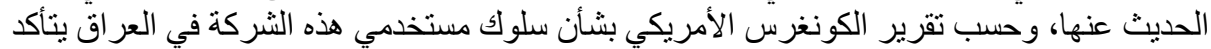

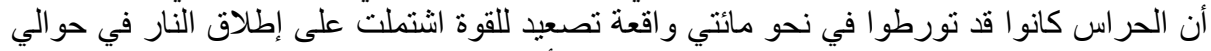

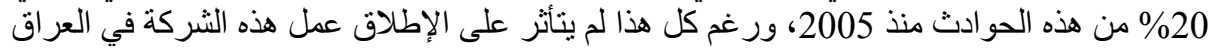
حنى كما توريز 2009.

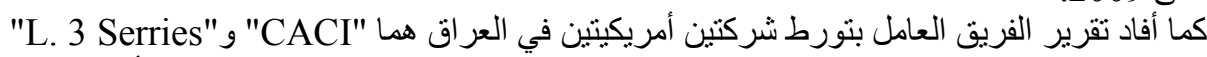

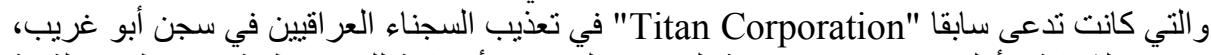

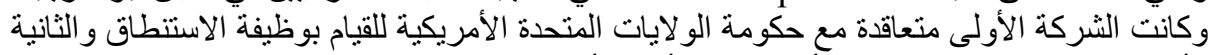

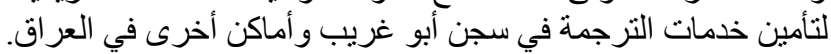

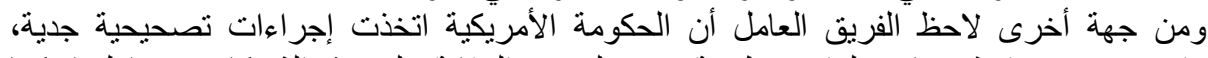
و اعتمدت مؤخر ا تشريعات ولوائح تنظيمية تهدف لتعزيز الرقابة على التى هذه الثركات التركات ومساءلتها، كما

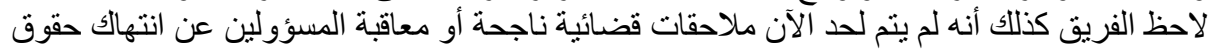
الإنسان.

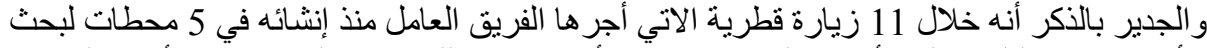

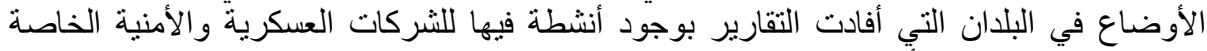
و المرنزقة وفي مقدنها أفغانستان، إكو ادور، بيرو، جنوب إفريقيا وشيلي، العراق وغينيا الاستو ائية، 
فيجي وبريطانيا، هندور اس و الو لايات المتحدة الأمريكية.

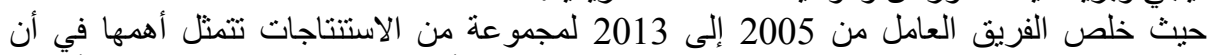

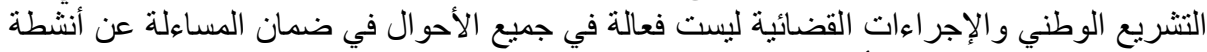

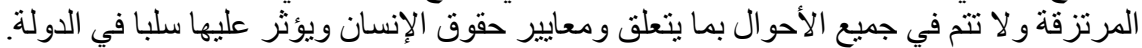

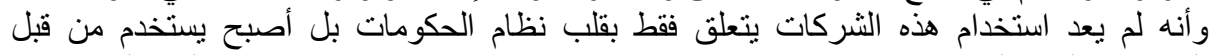

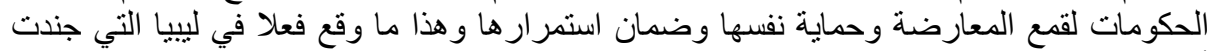

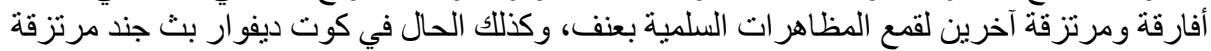

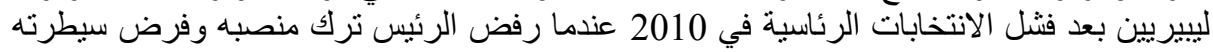
على الدولة (73). كما حذر الفريق العامل من عدم وجود رقابة وسيطرة فاعلة على أنشطة الثركات العسكرية والأمنية

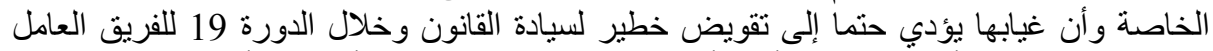

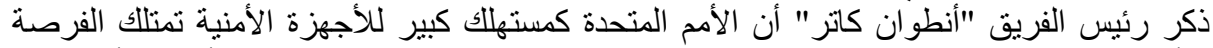

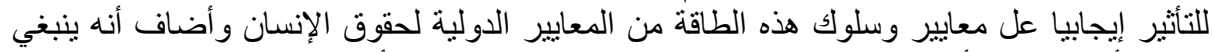

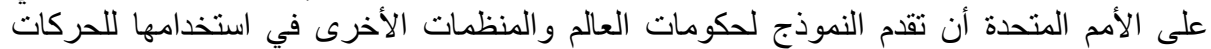

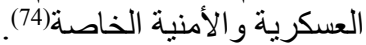

وفي الختام أسفرت أعمال الفريق العامل منذ توليه مهامه على إمكانية الوصول على وضلى وضع اتفاقية

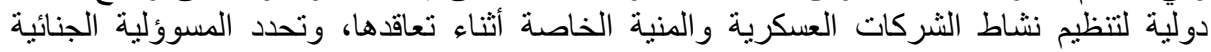

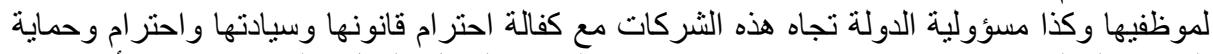

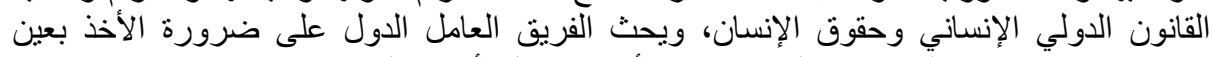

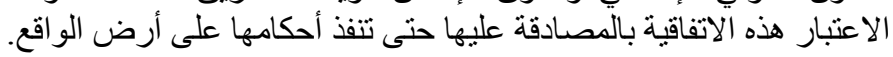
الفرع الثاني الفيكي

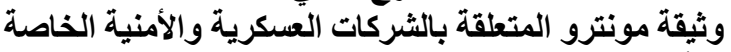

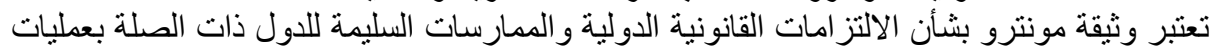

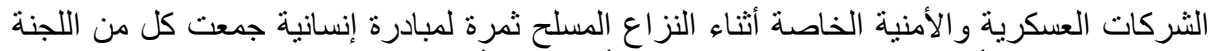

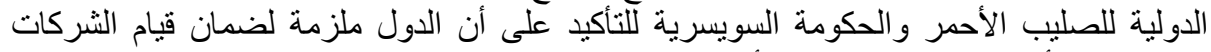

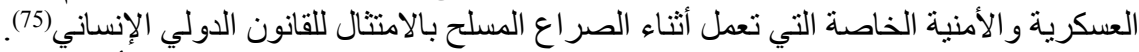

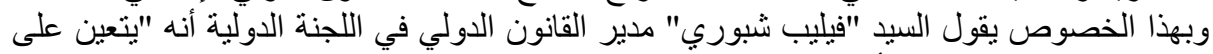

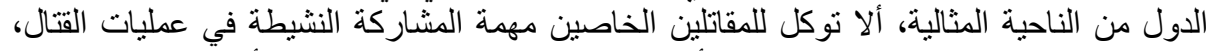

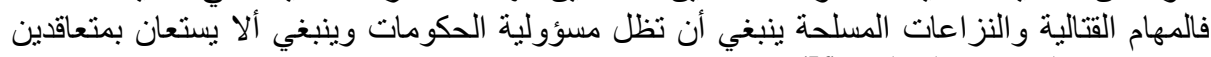

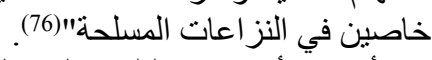

كما أضاف أن جميع البلدان التي تلجأ إل خدمات القطاع الخاص في النجات التال الأمني تكون مسؤولة

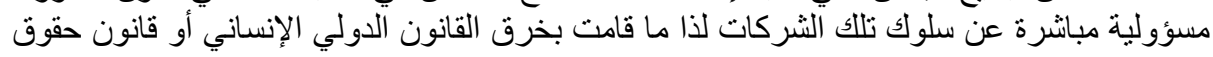
الإنسان.

و وعلى هذا الأساس تتضمن الوثيقة مجموعة من التوصيات للاول المتعاقدة مع الثركات العسكرية

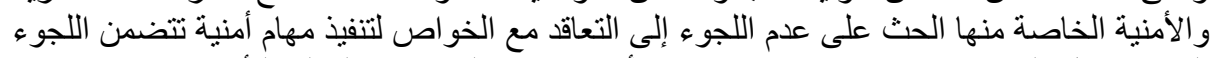

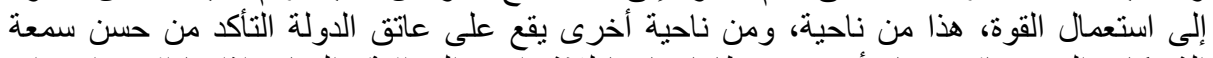

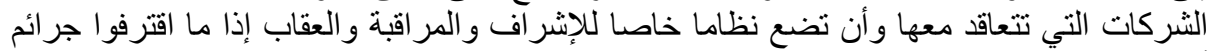

أثناء قيامهم بمهامهم (77).

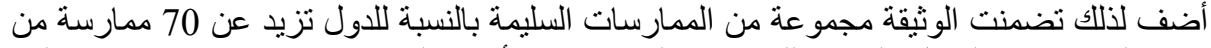

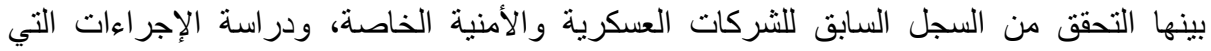

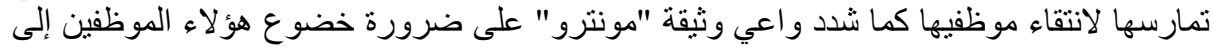




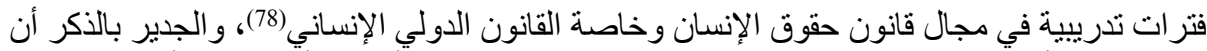

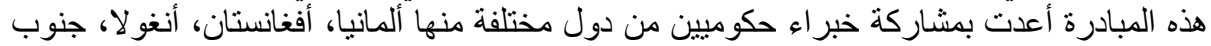

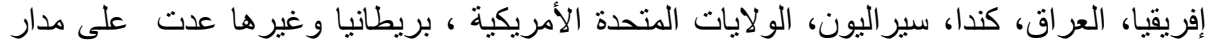

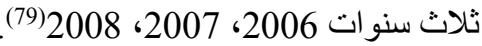

وخلال هذه الأعمال أكدت اللجنة الدولية على الفو ائد التي يمكن أن تجنيها البلدان و الثشعوب المنضررة

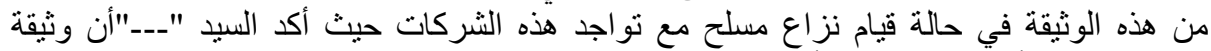

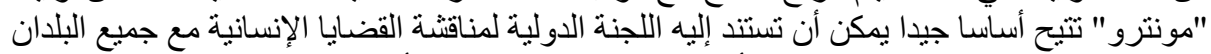

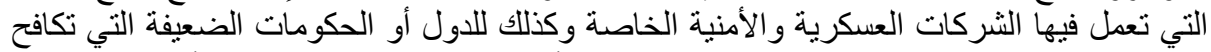

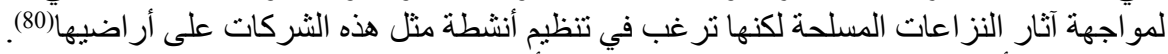

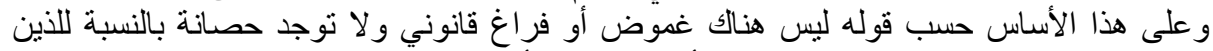

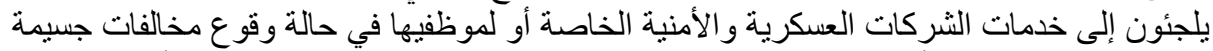

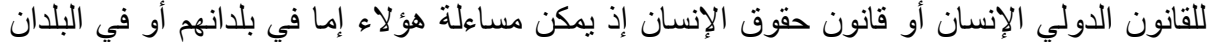

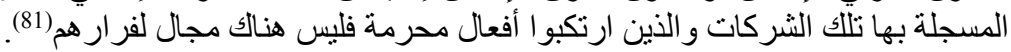

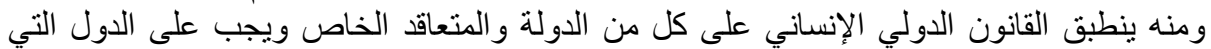

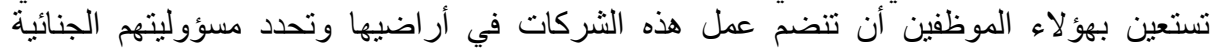

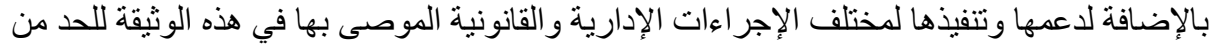
مختلف الانتهاكات الو اقعة في الصر اعات الدولية.

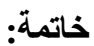

يستخلص من خلال در اسة موضو ع المرتزقة في القانون الدولي الإنساني مجموعة النتائج التالية:

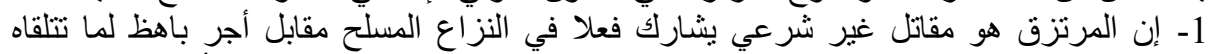

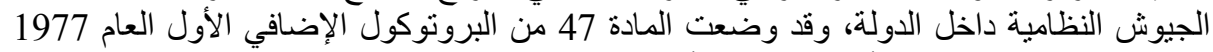

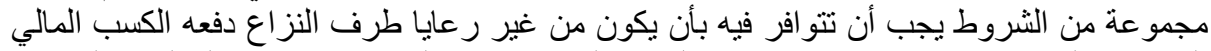

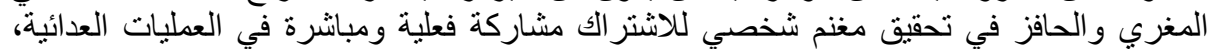
وبالتالي ليس لديه مبادئ أو قضية يدافع عنها.

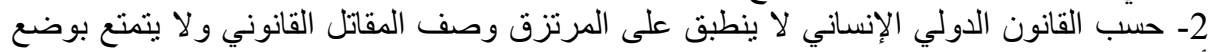

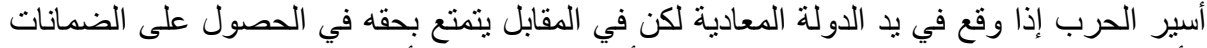

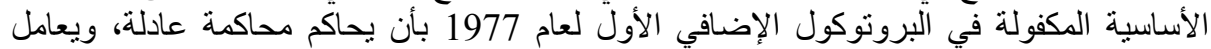

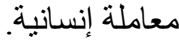

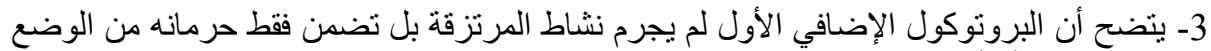

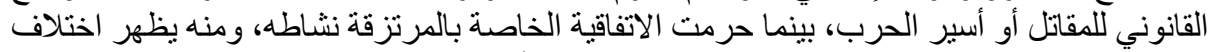

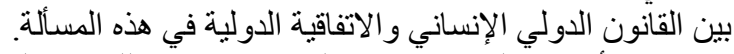

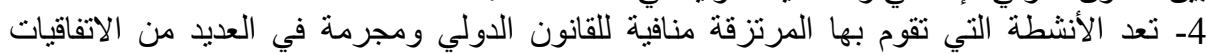

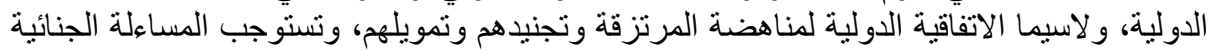

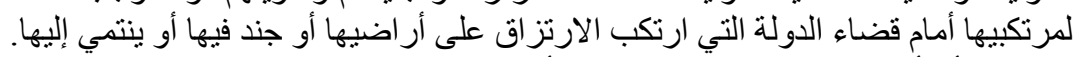

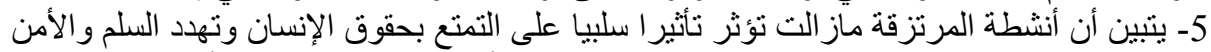

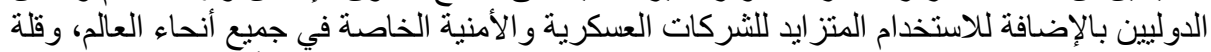

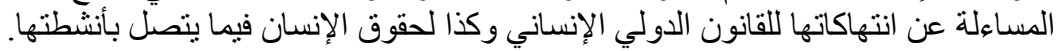

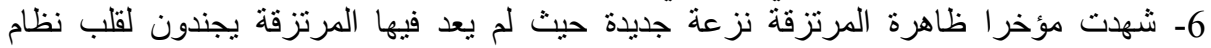

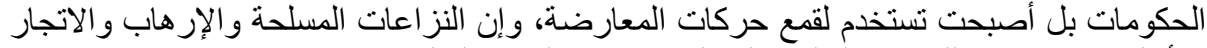

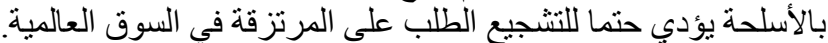
7ـ اتخذت مؤخر ا ظاهرة الارتزاق صورة أخرى مضللة في الوسط الدونية الدئ وهي الثركات العسكرية 
و الأمنية الخاصة التي تلعب دورا أساسيا في النزاعات الدولية والحروب الأهلية وتنتهلك القانون الدولي

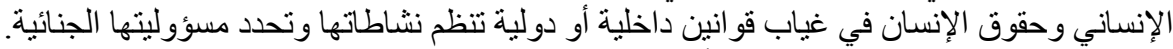

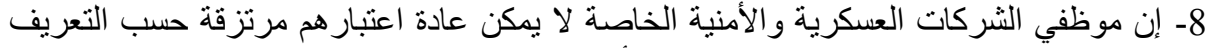

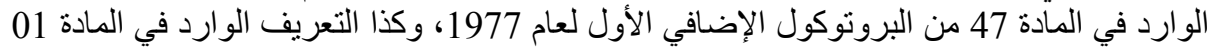

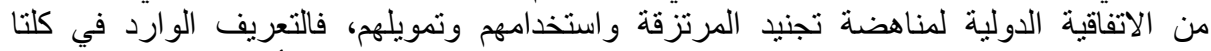

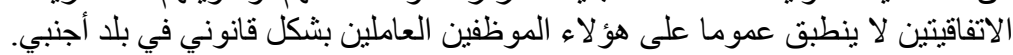

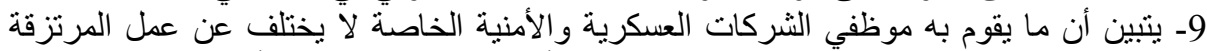

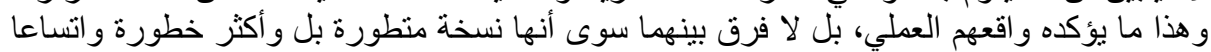

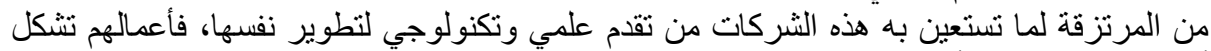

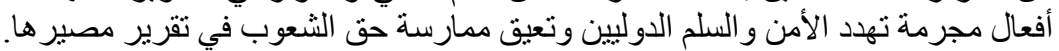

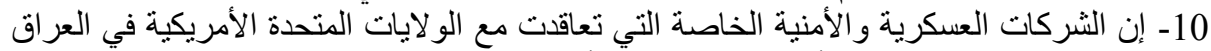

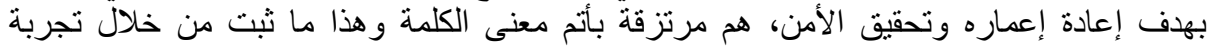

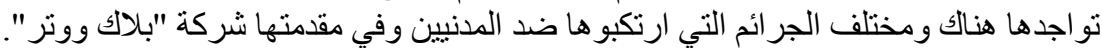

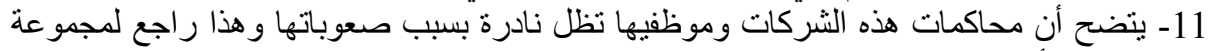

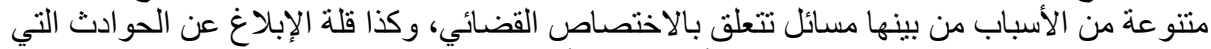

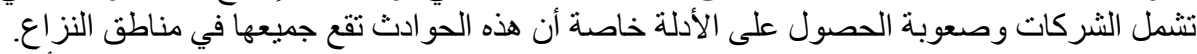

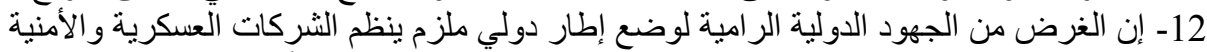

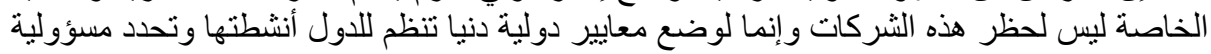
موظفيها في حالة خرقهم للقانون.

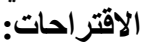

1- ضرورة قيام الدجتمع الدولي بتجريم نثاطات المرتزقة بكافة أثكالها وحظر ها بشكل قاطع، وكذا

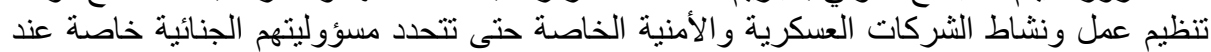
ارتكابهم جر ائم تهدد الأمن و السلم الدوليين.

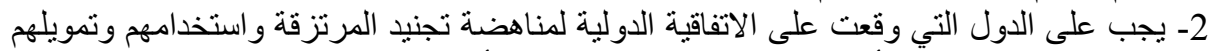

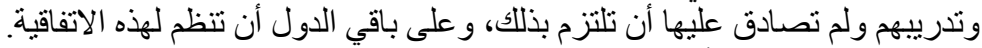

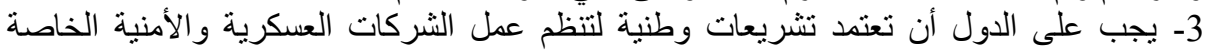
وتضمن تنفيذها الفعلي.

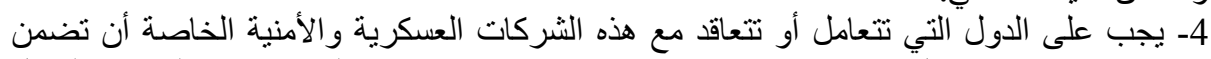

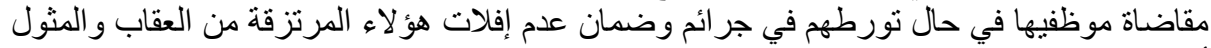

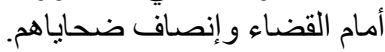

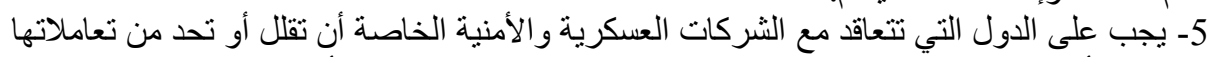

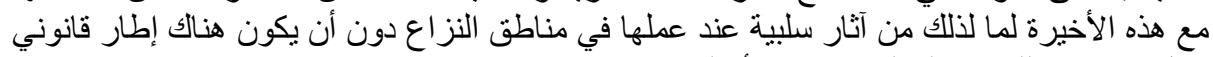
تكفل احتر امها للقانون الدولي الإنساني أو لحقوق الإنسان. 
1- حمد العسيلي (محمد)، المركز القماني والقانوني لأسرى الحرب في القانون الدولي الإنساني، الطبعة الأولى،

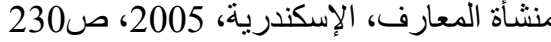

2-الأشعل (عبد الله)، ظاهر المرنزقة في العلاقات الدولة الدانية وخطر ها على العالم الثالث، المجلة المصرية

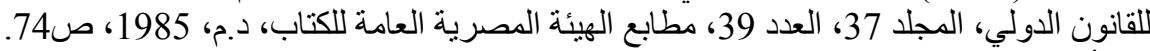

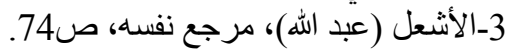

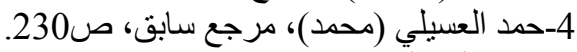

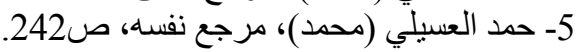

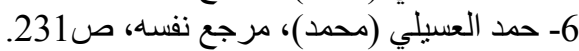

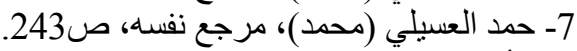

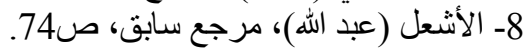

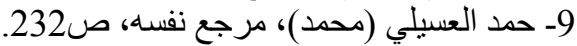

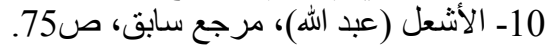

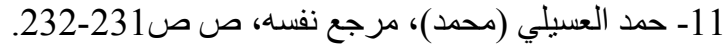

12- الجندي (عنان)، المرنزقة والقانون الدولي، المجلة المصرية للقانون الدولي، المجلد 41، الجمعية

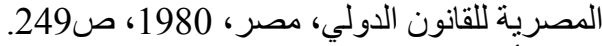

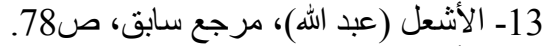

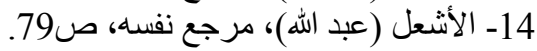

15-Fallah (Katherine), Les actures privés : Le statut juridique des mercenaires dans un conflit armé, revue international de la croix rouge, 2006, http://www.icrc.org.

$$
\text { 16- حمد العسيلي (محمد)، مرجع سابق، صدمد)، مرجع نفساه، ص247. }
$$

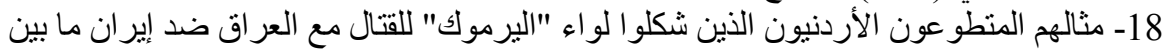

.1988-1980

19-ميلزر (نيلس)، المشاركة المباشرة في العمليات العدائية بموجب القانون الدولي الإنساني، اللجنة

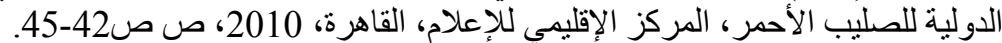

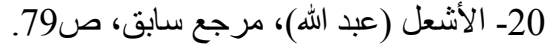

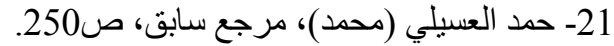

22- تتمثل هذه القرارات في القرار 239 الصادر في

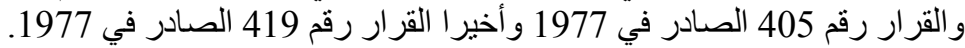

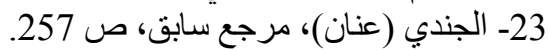

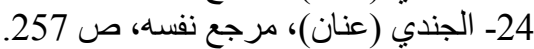

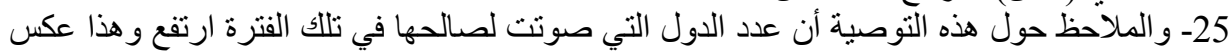

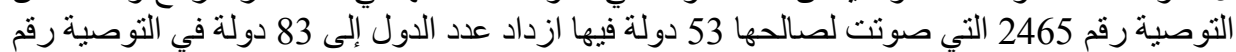

.3130

26- سعد الله (عمر)، تقرير المصير السياسي للشعوب في القانون الدولي المعاصر ، المؤسسة الوطنية

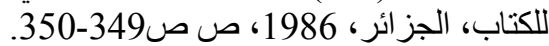

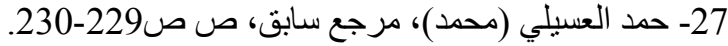

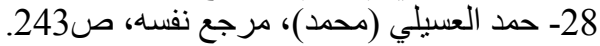


29-Habib (Eherari), Le mercenariat dans : Droit international pénal, A.

Pedone, France ; 2000 ; p468.

$$
\begin{aligned}
& \text { 30-الحاج (بهلول)، المقاتلون أثناء النزاعات المسلحة، دار هومة، الجزائر، 2014، ص78. }
\end{aligned}
$$

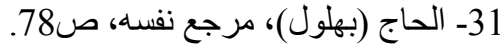

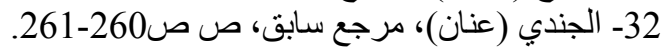

33-Josiane (Tercient); Les mercenaires et lke droit international, annuaire français de droit international, 1977, www.persee.fr/web/revues/rome/prexopt. 34- ويفره (بورشيت)، ديرك (وبوك)، المرتزقة في إفريقيا، الطبعة الأولى، المؤسسة العربية للاراسات

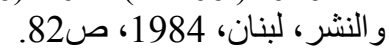

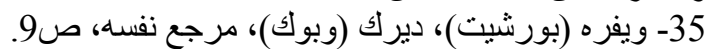

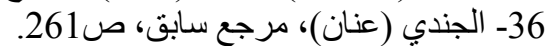

37-Fallah (Katherine), Op.cit, p170.

38- رضوان (محمد)، المبادئ العامة للقانون و العدالة الدولية، إفريقيا الثرق، المغرب، 2010،

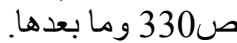

39-Fallah (Katherine), Op.cit, p169.

40-المادة 4 من الاتفاقية الثالثة لجنيف المؤرخة في 12 أوت 1949، 1959، اللجنة الدولية للصليب الأحمر،

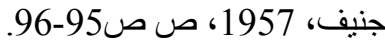

41-Martin (Eaton), New rules for victims of armed conflicts, commentary on the two 1977 protocols additional to the Genève conventions of 1949, p267. 42- Pictet (Jeant), Commentaire de protocoles additionnels 1977, Comité international de la croix rouge, Genève, 1986, p577.

43-Martin (Eaton), Op.cit, p271.

44ـعلقم (شريف)، موسو عة القانون الدولي الإنساني، الطبعة الأولى، اللجنة الدولية للصليب الحمر ،

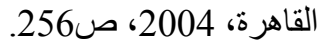

و5-بلوم (ويليام)، الدولة المارقة دليل إلى الدولة العظمى الوحيد في العالم، الطبعة الأولى، العدد 463،

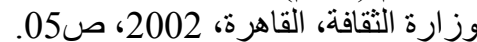

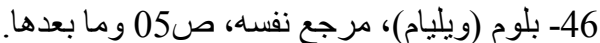

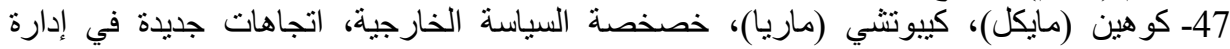

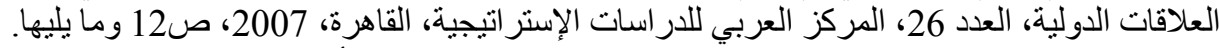

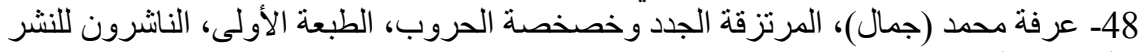

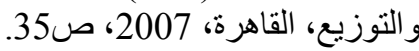
49- عبد الحميد نبيه (نسرين)، جر ائم الحرب، المكتب الجامعي الحديث، د.م، 2011، ص ص398-

50- شريف (محمد)، المرتزقة الجدد والقانون الدولي، دار المعارف للنشر والتوزيع، القاهرة، 2004، ص ص261.

51- الهيئة المصرية للاستعلامات، شركات الأمن ودور ها في إفريقيا، العدد 2006، مجلة آفاق إفريقيا،

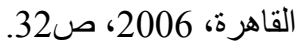

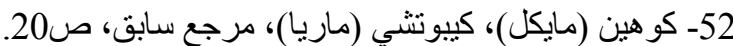

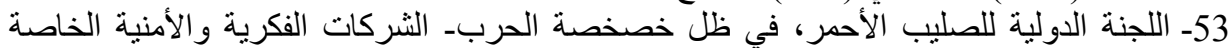

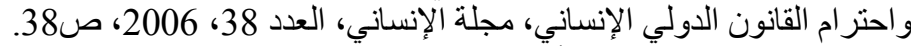

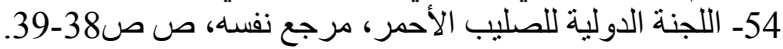


55- اللجنة الدولية للصليب الأحمر، مرجع نفسه، ص39.

56- أبو الخير السيد مصطفى (أحمد)، مستقبل الحروب: الثربة الثركات العسكرية الدولية الخاصة، مجلة

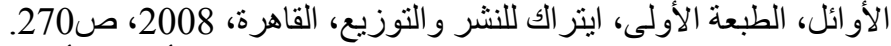

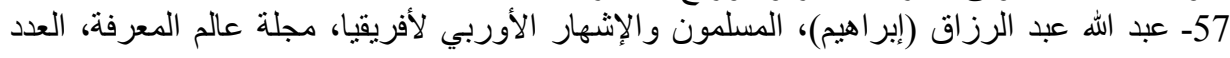

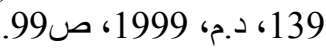

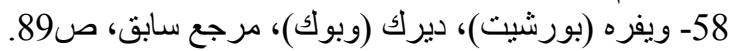

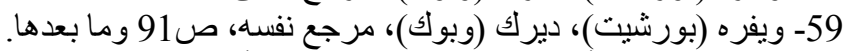

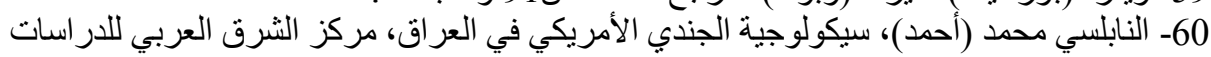

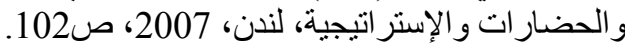

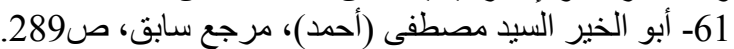

62- عبد العزيز المدور (هبة، الحماية من التعذيب في إطار الاتفاقية الدولية والإقليمية، منشورات الحلي

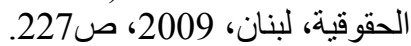

63- أبو الخير السيد مصطفى (أحمد)، مرجع سابق، صاندة ص289.

64- الحامد (ر ائد)، شركات الحماية الأمنية في العر اق، دار بابل للار اسات و الإعلام، العراق، 2006،

ص ص23.

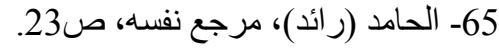

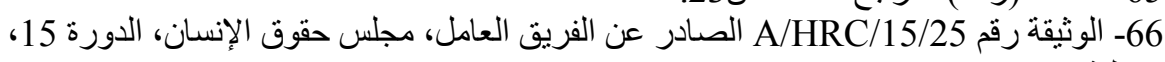
جويلية المونة 67- الوثيقة رقم A/HRC/15/25

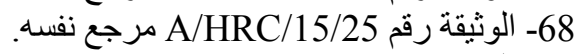

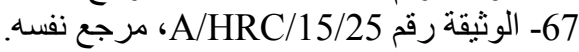

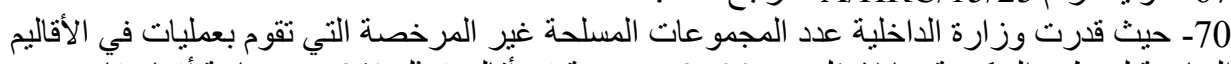

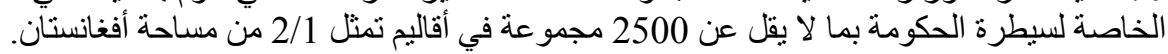
A- 71 الوثيقة رقم

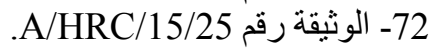

73- الوثيقة رقم A/HRC/18/32 الصفادرة عن مجلس حقوق الإنسان في الدورة الثامنة عشر، 4 جويلية 7011 2013

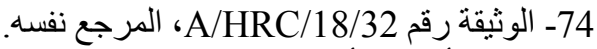
Gihr-75، أخبار الأمم المتحدة، بداية الدورة 19 للفريق المعني باستخدام المرتزقة، 2013، 2013، منوفر على موقع: 76- نركي فيصل (رشيد)، وثيقة مونترو المتعلقة بالثركات العسكرية والأمنية الخاصة، المنتدى العام، www. $<$ sawdiinRorus.com $>$ forum 2008، متّوفر على موقع: (رنيد)،

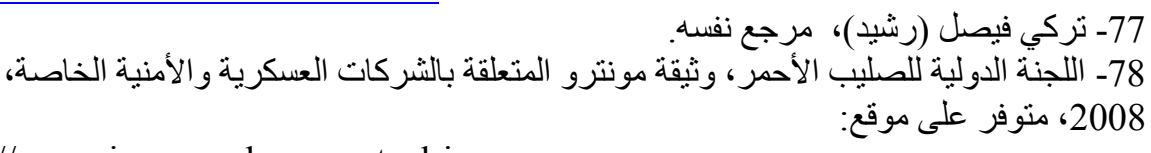
http://www.icrc.org documents.drix

$$
\begin{aligned}
& \text { 79- الوثثقة رقم A/HRC/10/14 الصادرة عن مجلس حقوق الإنسان في الدورة العاثرة، } 21 \\
& \text { جانفي } \\
& \text { 80- الوثنقة رقم A/HRC/10/14، الوثئه رف المرجع نفسه. } \\
& \text { 81- الوثنقة رقم 80/14 الوثة A/HRC/10/14، المرجع نفسه. }
\end{aligned}
$$

